\title{
(M4CT-18IN0707093) Investigating Electrochemical Impedance Spectroscopic (EIS) Measurement of Surrogate Oxide at High Temperatures
}

Hongqiang $\mathrm{Hu}$, Yanhao Dong, Ju Li, Claire Xiong, Mike Hurley

March 2018

The INL is a U.S. Department of Energy National Laboratory operated by Battelle Energy Alliance

Idaho National Laboratory 


\title{
(M4CT-18IN0707093) Investigating Electrochemical Impedance Spectroscopic (EIS) Measurement of Surrogate Oxide at High Temperatures
}

\author{
Hongqiang Hu, Yanhao Dong, Ju Li, Claire Xiong, Mike Hurley
}

March 2018

Idaho National Laboratory Idaho Falls, Idaho 83415

http://www.inl.gov

Prepared for the

U.S. Department of Energy

Under DOE Idaho Operations Office

Contract DE-AC07-05ID14517 


\section{DISCLAIMER}

This information was prepared as an account of work sponsored by an agency of the U.S. Government. Neither the U.S. Government nor any agency thereof, nor any of their employees, makes any warranty, expressed or implied, or assumes any legal liability or responsibility for the accuracy, completeness, or usefulness, of any information, apparatus, product, or process disclosed, or represents that its use would not infringe privately owned rights. References herein to any specific commercial product, process, or service by trade name, trade mark, manufacturer, or otherwise, does not necessarily constitute or imply its endorsement, recommendation, or favoring by the U.S. Government or any agency thereof. The views and opinions of authors expressed herein do not necessarily state or reflect those of the U.S. Government or any agency thereof. 



\section{EXECUTIVE SUMMARY}

The objective of this work package is to develop electrochemical impedance spectroscopic (EIS) techniques for the in-pile measurement of changes in solid state chemistry of fuels and materials in coupling with model simulation and material characterization. This work package will involve the initial development of electrochemical sensing technologies for measuring spatialand time-resolved changes in fuel and cladding chemistry. Specific attention will be paid to monitoring changes in fuel stoichiometry, monitor cladding hydride formation and deformation, and cladding corrosion.

The planned work during this period was focused on theoretical investigation on high temperature impedance of material, establishing experimental capabilities, including high temperature EIS under controlled gas atmosphere, atom probe tomography (APT), Raman Spectroscopy, and Synchrotron XRD. Future work will focus on starting the electrochemical sensor development, targeting the dielectric response of oxide fuels and cladding oxides/hydrides under thermodynamic equilibria, during transients, and under irradiation.

Three main achievements are summarized in this report for the FY17 carry-over. First, theoretical investigation on high temperature impedance of material were conducted and spatial distribution of defects and equivalent resistivity in stoichiometric oxides under a temperature gradient were analyzed. Second, a laboratory for EIS measurement at high temperature was established and the laboratory instruction (LI) for conducting experiments was approved; and the impedance of $\mathrm{CeO} 2$ at $800 \mathrm{C}$ was examined and its electrical conductivities were analyzed and compared with other reported data. In addition, the capabilities of advanced characterization wer established including high temperature Ramen, atom probe tomography (APT) and SEM, and samples including $\mathrm{Zr} 4$ and $\mathrm{CeO} 2$ were characterized. 


\section{CONTENTS}

EXECUTIVE

SUMMARY

ACRONYMS.

vi

1. Project Overview and Objective........................................... 1

2. Theoretical Investigation on High Temperature Impedance of Materials ...... 2

2.1 Perspectives on High-Temperature Impedance in Zirconia \& Ceria........ 2

2.2 Spatial Distribution of Defects and Equivalent Resistivity in Stoichiometric 10

Oxides under a Temperature Gradient ..........................

3. Electrochemical Impedance Systems Setup and Measurement........... 14

4. Establishing Capability of Advanced Characterization ....................... 24

5. Reference......................................................................... 29 


\title{
ACRONYMS
}

\author{
APT atom probe tomography \\ EIS electrochemical impedance spectroscopy \\ FE Finite element \\ TEM Transmission Electron Microscopy \\ XRD X-ray diffraction
}


(M4CT-18IN0707093)

Investigating Electrochemical Impedance Spectroscopic (EIS) Measurement of Surrogate Oxide at High Temperatures

\section{Project Overview and Objective}

\section{Background for Current Milestones}

Presently, chemical evolution over the lifetime of the fuel and cladding can only be inferred using post-irradiation examination. This limitation presents a significant obstacle for achieving a comprehensive and unified understanding of fuel and cladding chemical evolution. As an alternative to post-irradiation measurements, we are making progress in establishing a new sensing technique to monitor and measure in-pile changes in chemistry in oxides and hydrides fuel/cladding changes using electrochemical impedance spectroscopy (EIS).

EIS is a well-established technique for determining interfacial phenomena and monitoring surface reactions such as oxidation. In addition, EIS has been successfully used to resolve ionic conduction mechanisms influenced by microstructural and chemistry changes in high temperature oxides in-situ for solid-oxide fuel cell applications. Moreover, EIS has recently been successfully implemented for in-core sensing (Jenssen et al., 2017) of Zr-alloy corrosion.

Rationale: A sensor provides a method of interrogation and requires response signals that are sensitive to changes in the specific phenomena of interest. EIS has been selected as a practical sensing technique for in-pile applications because it is known to be useful for sensing chemical changes similar to what is desired for in-core nuclear materials and the technical barriers to implementing are comparatively low.

- An EIS sensor requires 2 separate electrodes with electrical connections for input and output signal delivery.

- EIS, along with any sensor that relies on an electrical output signal (e.g. thermocouple, capacitive strain gauge), must be calibrated in order to associate the sensor response with a physical change or process.

Strategy: Demonstrate EIS sensing feasibility for nuclear materials applications. Initial focus on a fuel $\left(\mathrm{UO}_{2}\right)$ and a cladding material $(\mathrm{Zr})$ separately in non-irradiation conditions and demonstrate changes in materials chemistry are detected by EIS. Use complementary techniques to characterize changes in chemistry to validate EIS signal is sensitive to verified chemistry changes. Then build to fuel/clad interactions, fission gas characterization, and irradiation effects. 
Related applications have formed the basis for EIS implementation for rector core fuel/cladding chemistry sensing and current R\&D activities are underway to establish the experimental capability to validate EIS sensing capabilities and implement EIS sensing in core.

The objective of this work package is to develop electrochemical impedance spectroscopic (EIS) techniques for the in-pile measurement of changes in solid state chemistry of fuels and materials in coupling with model simulation and material characterization. This work package will involve the initial development of electrochemical sensing technologies for measuring spatialand time-resolved changes in fuel and cladding chemistry. Specific attention will be paid to monitoring changes in fuel stoichiometry, monitor cladding hydride formation and deformation, and cladding corrosion.

The planned work during this period was focused on theoretical investigation and prediction, establishing experimental capabilities, including high temperature EIS under controlled gas atmosphere, atom probe tomography (APT), Raman Spectroscopy, and Synchrotron XRD.

Future work is focused on starting the electrochemical sensor development, targeting the dielectric response of oxide fuels and cladding oxides/hydrides under thermodynamic equilibria, during transients, and under irradiation.

\section{Theoretical Investigation on High Temperature Impedance of Materials}

\subsection{Perspectives on High-Temperature Impedance in Zirconia \& Ceria}

\subsubsection{Background: materials perspectives}

Zirconia and ceria are the state-of-art solid oxygen ion conductor, with wide applications in solid oxide fuel/electrolyzer cell (SOFC/SOEC). Naturally, due to extensive electrochemical applications, their electrical properties (commonly revealed by impedance technique) has been paid much attention for decades. Both zirconia and ceria have fluorite $\left(\mathrm{CaF}_{2}\right)$ structure, where oxygen anions adopt simple cubic packing and cations fill in half of interstitial sites (see Figure 1). This is the iso-structure of $\mathrm{UO}_{2}$, so they are good representatives in our preliminary studies to demonstrate the methodology. Fluorite structure is well-known for its fast anion diffusion/high ionic conductivity, such as $\mathrm{F}^{-}$diffusion in $\mathrm{CaF}_{2}$ and $\mathrm{MgF}_{2}$, and $\mathrm{O}^{2-}$ diffusion in $\mathrm{CeO}_{2}, \mathrm{ZrO}_{2}$ and $\mathrm{UO}_{2}$. Mechanistically, both (i) a high mobility and (ii) a large charge carrier concentration give rise to the high ionic conductivity. For (i), the barrier of $\mathrm{O}^{2-}$ vacancy migration in $\mathrm{ZrO}_{2}$ and $\mathrm{CeO}_{2}$ is about $0.5 \mathrm{eV}$, which can be easily activated at $600-800{ }^{\circ} \mathrm{C}$. The small migration barrier is directly related to the bonding environment of $\mathrm{O}^{2-}$, which has only 4 cation first nearest neighbor. In comparison, the cation (bonded by $8 \mathrm{O}^{2-}$ as the first nearest neighbor) migration is much more difficult, with a barrier of 3-5 eV (Dong et al., 2017). For (ii), the main charge carrier 
is usually oxygen vacancy created by extrinsically doped low-valent cation, e.g. $\mathrm{Y}^{3+}$ or $\mathrm{Ca}^{2+}$ doping in $\mathrm{ZrO}_{2}$ and $\mathrm{Gd}^{3+}$ doping in $\mathrm{CeO}_{2}$. (Oxygen vacancy also dominates in understoichiometric $\mathrm{UO}_{2-x}$, but oxygen interstitial is more critical in over-stoichiometric $\mathrm{UO}_{2+x}$.) Using the Kröger-Vink notations, the defect reactions can thus be written as

$$
\begin{aligned}
& \mathrm{Y}_{2} \mathrm{O}_{3}=2 \mathrm{Y}_{\mathrm{Zr}}^{\prime}+\mathrm{V}_{\mathrm{O}}^{\bullet}+3 \mathrm{O}_{\mathrm{O}}^{\times} \\
& \mathrm{CaO}=\mathrm{Ca}_{\mathrm{Zr}}^{\prime \prime}+\mathrm{V}_{\mathrm{O}}^{\bullet \bullet}+\mathrm{O}_{\mathrm{O}}^{\times} \\
& \mathrm{Gd}_{2} \mathrm{O}_{3}=2 \mathrm{Gd}_{\mathrm{Ce}}^{\prime}+\mathrm{V}_{\mathrm{O}}^{\bullet \bullet}+3 \mathrm{O}_{\mathrm{O}}^{\times}
\end{aligned}
$$

Therefore, the ionic conductivity is expected to increase with the doping concentration. Such a dependence is shown in Figure 2, where the conductivity peaks at an intermedium dopant concentration (for YSZ, it is around $8 \mathrm{~mol} \% \mathrm{Y}_{2} \mathrm{O}_{3}$, which is why $8 \mathrm{YSZ}$ is most popular). The decrease in the high-concentration regime is attributed to stronger defect-defect interactions, which lowers the mobility of oxygen vacancy or the concentration of mobile carrier. This interaction also leads to a non-Arrhenius temperature dependence of ionic conductivity with an activation energy $\sim 0.5 \mathrm{eV}$ above $1150{ }^{\circ} \mathrm{C}$ likely to represent the actual barrier, which increases to $\sim 1.0 \mathrm{eV}$ at $500{ }^{\circ} \mathrm{C}$ likely due to the population decrease of mobile vacancies (Casselton, 1970). Since the non-Arrhenius behavior is quite weak, one can usually fit the data in a relatively wide temperature range with an "averaged" activation energy of $\sim 0.9 \mathrm{eV}$. Finally, as a reference line, the conductivity of $8 \mathrm{YSZ}$ is typically $\sim 0.01 \mathrm{~S} / \mathrm{cm}$ at $700{ }^{\circ} \mathrm{C}$.

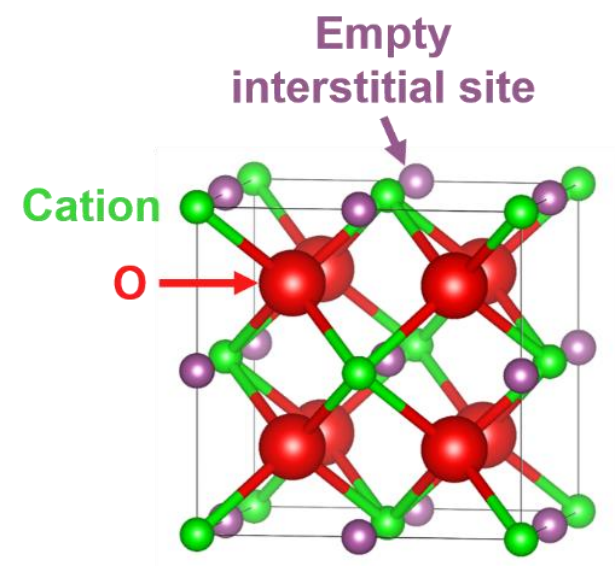

Figure 1 Crystal structure of cubic zirconia/ceria. Oxygen ions in red, cations in green and unfilled empty interstitial sites in purple. 


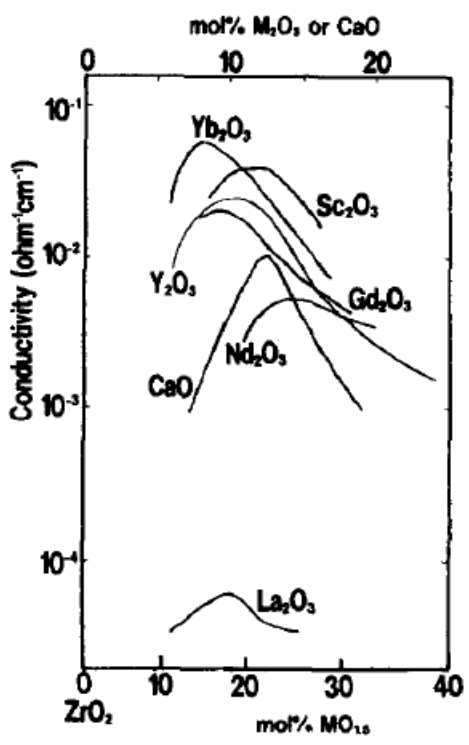

Figure 2 Variation of ionic conductivity in stabilized zirconia as a function of the dopant concentration (Yashima et al., 1996).

Closer inspections by AC impedance can distinguish the contribution of grain conductivity and grain boundary conductivity, since the two have vastly different characteristic frequencies (inverse of the $R C$ time). The measurements are usually done at about $300-400{ }^{\circ} \mathrm{C}$, since the characteristic frequencies will all exceed the instrument limit (typically $<100 \mathrm{MHz}$ ) at higher temperatures. One such example is shown in Figure 3, where the high-frequency semicircle on the left pertains to the grain conductivity and the low-frequency one on the right pertains to the grain boundary conductivity. (The very-right signals with the lowest frequencies are due to electrode kinetics, which requires charge transfer on triple phase line and is slower than the ion hopping process.) This is because grain boundary can block oxygen vacancy transport, with the attendant formation of a space charge layer around the grain boundary core. In doped zirconia, the data of dopant segregation and the (space-charge) model prediction suggest that oxygen vacancy is depleted in the space charge layer, which hampers the ionic conductivity. Efforts have been given to improve the ionic conductivity via engineering the grain boundary of doped zirconia (co-doping etc.), but YSZ is still the preferred choice for most use. ( $\mathrm{Sc}_{2} \mathrm{O}_{3}$ doped zirconia has a higher conductivity, however, its use is limited because $\mathrm{Sc}_{2} \mathrm{O}_{3}$ is much more expensive than $\mathrm{Y}_{2} \mathrm{O}_{3}$.) 


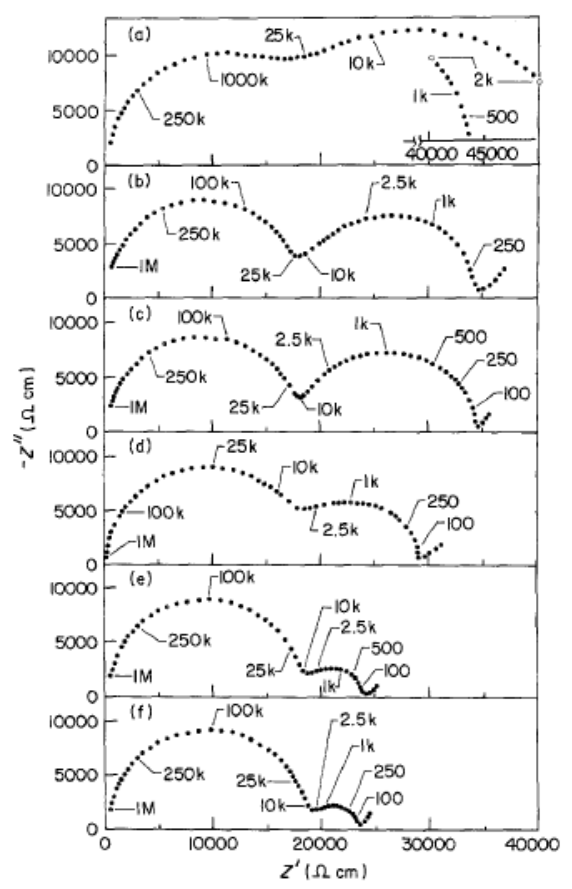

Figure 3 AC impedance spectrum measured at $401{ }^{\circ} \mathrm{C}$ for $10 \mathrm{~mol} \%$ yttria stabilized zirconia with a relative density and grain size of (a) $92 \%$ and $1.15 \mu \mathrm{m}$, (b) $97 \%$ and $6.1 \mu \mathrm{m}$, (c) $98 \%$ and $11.2 \mu \mathrm{m}$, (d) $98 \%$ and $15.1 \mu \mathrm{m}$, (e) $98 \%$ and $20.9 \mu \mathrm{m}$ and (f) $98 \%$ and $31.1 \mu \mathrm{m}$, respectively. The high-frequency semicircle on the left comes from grain conductivity and the low-frequency semicircle on the right comes from grain boundary conductivity (Badwal and Drennan 1987).

Zirconia has a very wide band gap, which guarantees minimum electron and hole concentrations over a wide range of oxidizing and reducing conditions. It makes doped zirconia an ideal electrolyte material with the right combination of a high ionic conductivity and very small internal electronic leakage. The measured conductivities of oxygen ion, electron and hole of $8 Y S Z$ are shown in Figure 4 in which the ionic conductivity indeed dominates. It also supports the expectation from defect chemistry: The ionic conductivity remains a constant, while the electron and hole conductivity follows a $\mathrm{PO}_{2}{ }^{-0.25}$ and $\mathrm{PO}_{2}{ }^{0.25}$ dependence, respectively. In contrast, isostructural pure/doped ceria can be easily reduced and has a high electronic conductivity when it is in the reduced form because the existence of stable $\mathrm{Ce}^{3+} / \mathrm{Ce}^{4+}$ charge states. Nevertheless, zirconia can be reduced under very reducing conditions, e.g., when forcing a large current to pass through the ceramic held in argon. This process is known as current blackening, as the reduction turns zirconia into black (known as color center in ceramics). When the ability of the gas/electrode to generate lattice oxygens or oxygen vacancies to support the current density is inadequate, the so-called electrode polarization arises, which can also cause zirconia reduction. For $\mathrm{UO}_{2}$, it can adopt both under-stoichiometric form $\mathrm{UO}_{2-x}$ and the overstoichiometric form $\mathrm{UO}_{2+x}$ because more multi-stable valence of $\mathrm{U}$ cation. ( $\mathrm{U}$ has 6 valence electrons and can have stable $+3 /+4 /+5$ valence; Ce has 4 valence electrons and can have stable $+3 /+4$ valence; $\mathrm{Zr}$ has 4 valence electrons and can only have stable +4 valence unless some special conditions.)

Lastly, we may summarize the conductivity properties of doped zirconia (undoped zirconia cannot be made into pellets because the monoclinic-to-tetragonal phase transition would shatter 
the bulk sample upon cooling), pure/doped ceria and pure urania as following. Doped zirconia has a pure ionic conductivity (controlled by doping) and no oxygen potential/microchemical dependence. Pure ceria has mixed ionic and electronic conductivity upon reduction and poor conductivity under oxidizing conditions $\left(\mathrm{Ce}^{4+}\right.$ cannot be further oxidized) so its conductivity strongly depends on oxygen potential/microchemistry on the reducing side. In doped ceria, ionic conductivity dominates when reduction is modest and electronic conductivity arises when reduction is severe so its conductivity weakly depends on oxygen potential/microchemistry on the reducing side. Pure urania's conductivity strongly depends on oxygen potential/microchemistry on both the oxidizing and reducing sides. So the similarity of the testing materials to pure urania follows the ranking: doped zirconia<doped ceria<pure ceria.

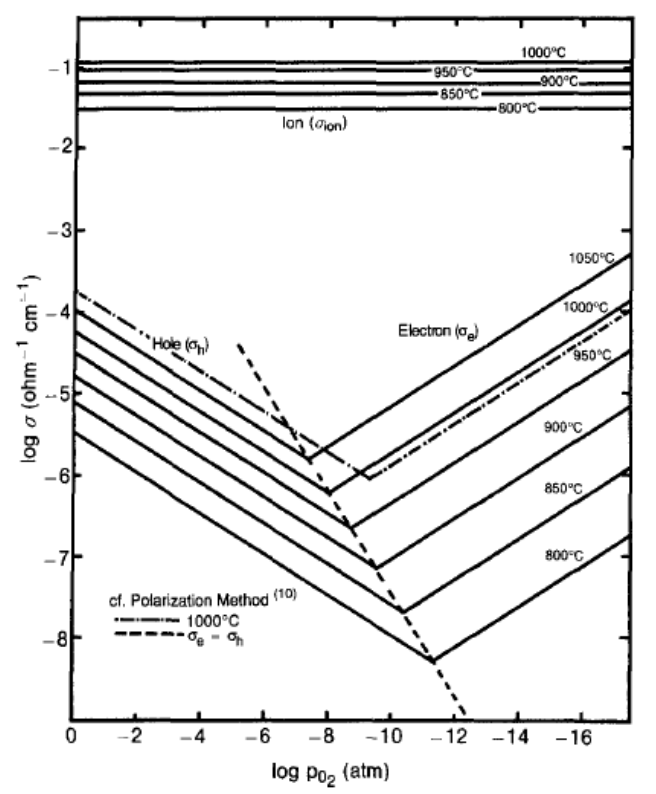

Figure 4 Oxygen ion, electron and hole conductivity in 8 mol\% $\mathrm{Y}_{2} \mathrm{O}_{3}$ stabilized $\mathrm{ZrO}_{2}($ Park et al., 1989).

\subsubsection{Methodology: impedance perspectives}

(1) Impedance as a function of temperature

As shown in Fig. 3, the grain and grain boundary impedance of zirconia (ceria as well) can be well captured around $300-400{ }^{\circ} \mathrm{C}$. However, we are targeting at higher temperature measurements, like $600{ }^{\circ} \mathrm{C}$ or higher. The highest scanning frequency we can possibly reach should be $\sim 1 \mathrm{MHz}$ (higher furnace temperature and more wiring cause more noise/error). In Fig. 5, I am showing how the impedance plot changes with (furnace/environment) temperature. The measurement was done on $8 \mathrm{~mol} \% \mathrm{Y}_{2} \mathrm{O}_{3}$ stabilized $\mathrm{ZrO}_{2}$ single crystal $(500 \mu \mathrm{m}$ from MTI crystal; http://www.mtixtl.com/squareysz100substrate.aspx $)$ using Pt electrode $\left(8 \mathrm{~mm}^{2}\right)$. At 450 $500{ }^{\circ} \mathrm{C}$, the high frequency part on the left side show some signals from the grain conductivity (no grain boundary in single crystal). However, the signals rapidly disappear if we increase the temperature to $>550{ }^{\circ} \mathrm{C}$. Above $600{ }^{\circ} \mathrm{C}$, we only see a depressed semi-circle, corresponding to the impedance of the electrodes. In Fig. 6, I am plotting the minimum frequency required to obtain some signal from the grain (which increases with temperature) using the data in Fig. 5. We may need to check with other systems as well. 

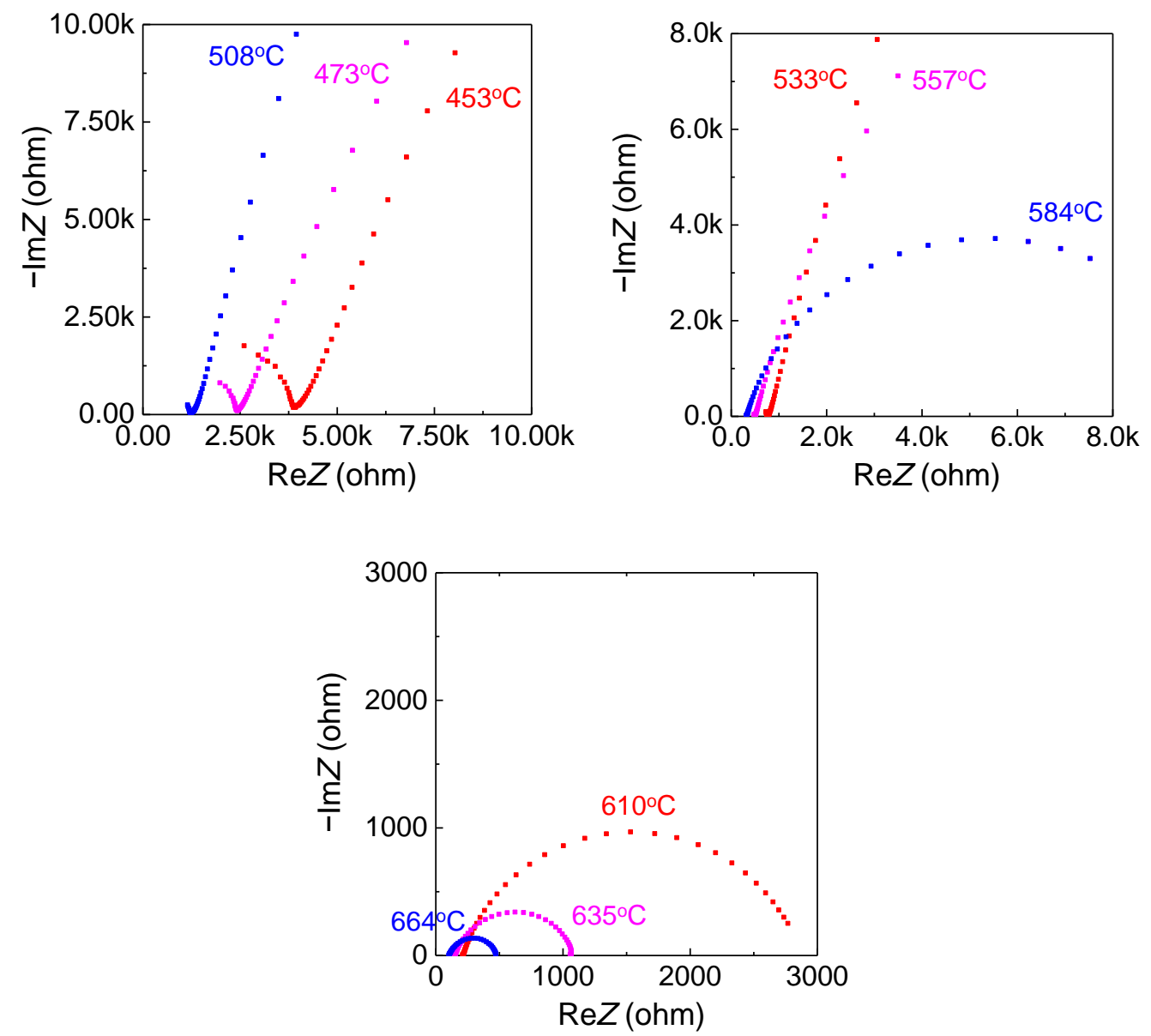

Figure 5 Impedance spectrum of $500 \mu \mathrm{m} 8 \mathrm{~mol} \% \mathrm{Y}_{2} \mathrm{O}_{3}$ stabilized $\mathrm{ZrO}_{2}$ single crystal. The real part of impedance $\operatorname{Re} Z$ was plotted vs. minus imaginary part $-\operatorname{Im} Z$. From left to right, one goes from high frequency to low frequency. All measurements were conducted using $0 \mathrm{~V}$ DC voltage and $5 \mathrm{mV}$ AC voltage, from $1 \mathrm{MHz}$ to $0.1 \mathrm{~Hz}$.

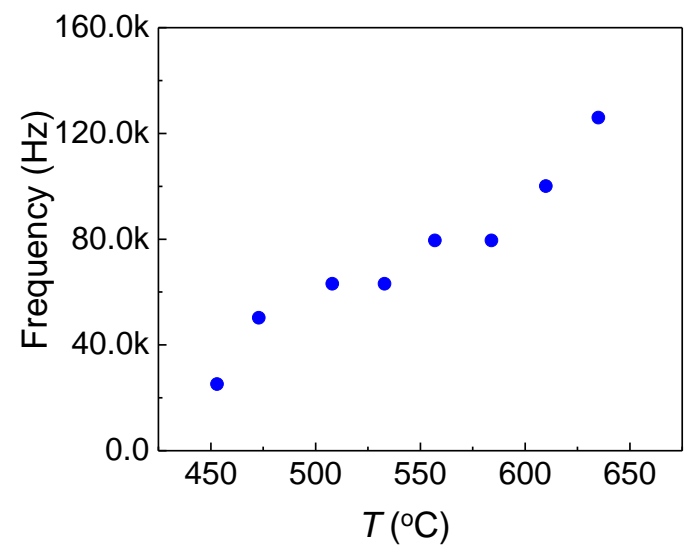

Figure 6 Minimum AC frequency to obtain grain-conductivity signal in $8 \mathrm{~mol}_{2} \mathrm{Y}_{2} \mathrm{O}_{3}$ stabilized $\mathrm{ZrO}_{2}$ single crystal. 
It would be nice if we can get signals from the grain and grain boundary, which can be then used to infer the microstructure evolution (cavitation, cracking etc.). In the worst case, we only get the impedance of electrodes, we can then get the intercept of the electrode semi-circle and know the "average" sample resistance. Cavitation and cracking will increase such resistance. Temperature increase, sintering (pore elimination) and grain growth (less grain boundary blocking) will decrease such resistance. Local chemistry change (nonstoichiometry, which could cause more electronic conduction: increased electron/hole population) also matters. But these effects are hard to separate.

(2) Distribution of relaxation time

A perfect semi-circle in the Cole-Cole plot (real part of impedance $\operatorname{Re} Z$ was plotted vs. minus imaginary part $-\operatorname{Im} Z$ ) refers to a resistor and a capacitor $R C$ in parallel. However, in reality, the semi-circles are often depressed (e.g., Figure 5). People explained this using the concept of distribution of relaxation time. Basically, one can fit the depressed semi-circle by many $R C$ component, with their $R C$ time following certain distribution (like Gaussian). More details can be found in a published work (Leonide et al., 2008).

(a)

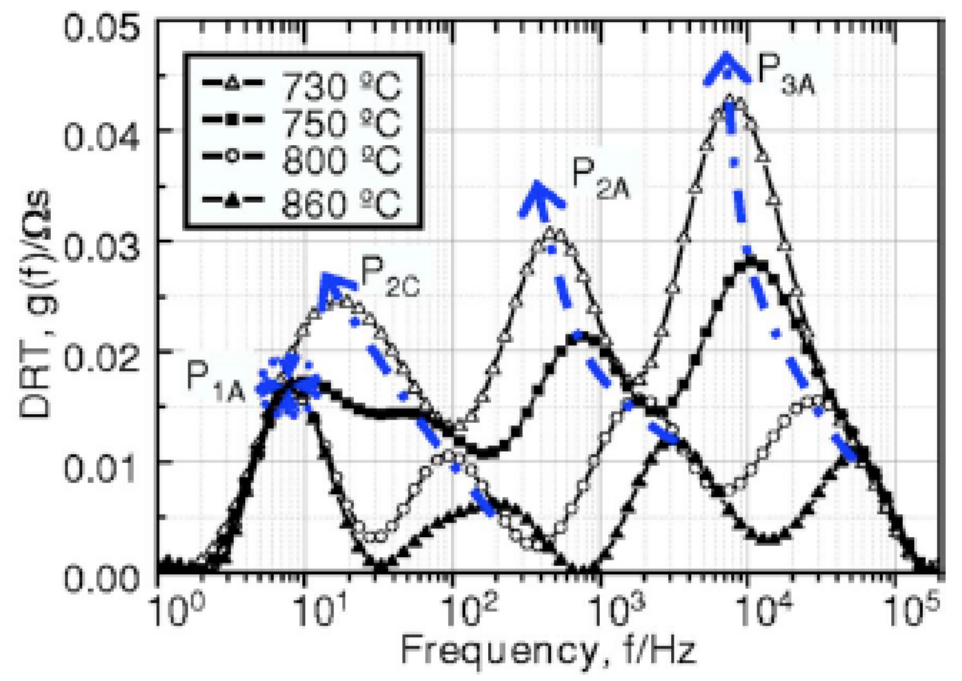

Figure 7 Calculated distribution of relaxation time (DRT) for solid oxide fuel cell at different temperatures. $\mathrm{P}_{1 \mathrm{~A}}, \mathrm{P}_{2 \mathrm{C}}, \mathrm{P}_{2 \mathrm{~A}}, \mathrm{P}_{3 \mathrm{~A}}$ refer to different rate-limiting processes (Leonide et al., 2008).

(3) Impedance with DC bias

We discussed of using a DC bias while measuring the AC impedance. The DC bias has two effects. First, the DC voltage will polarize the electrode and drive the chemical reactions on the electrode/electrolyte interface. So the electrode kinetics change and the impedance of the electrodes will decrease. Second, a large DC bias will cause Joule heating (determined by input power per volume=field strength* current density $=$ field strength $^{2} /$ resistivity $=$ current density ${ }^{2 *}$ resistivity). One practical example is shown in Fig. 8. The measurements were conducted in dense 3 mol\% $\mathrm{Y}_{2} \mathrm{O}_{3}$ stabilized $\mathrm{ZrO}_{2}$ polycrystals at $1200{ }^{\circ} \mathrm{C}$. As we increase the DC current density from 0 to $12.5 \mathrm{~A} / \mathrm{cm}^{2}$, the sample resistance (revealed by the left-intercept of the electrode-impedance semi-circle) decreases due to Joule heating. The heating is expected to be 
more in the inner core and less in the outer surface (bulk Joule heating vs. surface radiation cooling). This technique could be used to mimic the temperature profile under radiation (also bulk heating vs. surface cooling). It would be interesting to know how the impedance looks like at lower temperatures, preferably with some signals from the grain/grain boundary. If the resistivity/conductivity-temperature relationship is known for the electrolyte, we can then use the measured sample resistance (electrode contributions already excluded) to back-calculate the temperature profile. One example is shown in Fig. 9 using the data from Fig. 8, assuming a uniform sample temperature for simplicity.

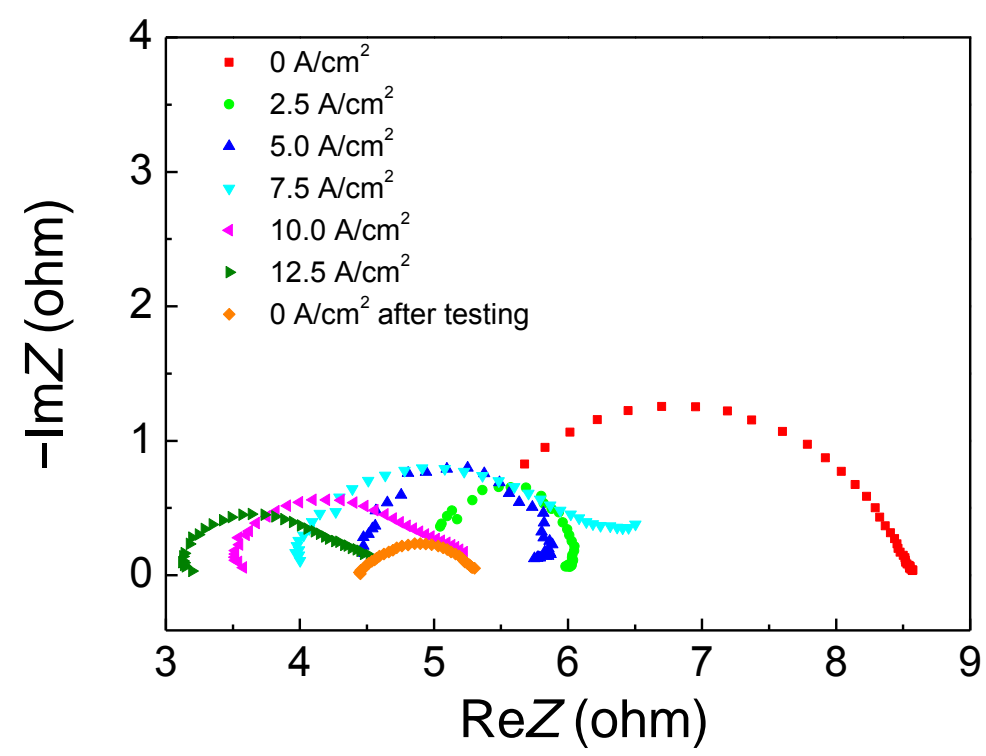

Figure 8 Impedance spectra in Cole-Cole plots for 3YSZ under different DC current density. The AC magnitude is $0.0625 \mathrm{~mA} / \mathrm{cm}^{2}$ (root mean squared). The frequency was swept from 300 $\mathrm{kHz}$ to $100 \mathrm{~Hz}$ at $2 \mathrm{~s}$ interval, recorded from the left to the right along each curve. Furnace temperature: $1200{ }^{\circ} \mathrm{C}$.

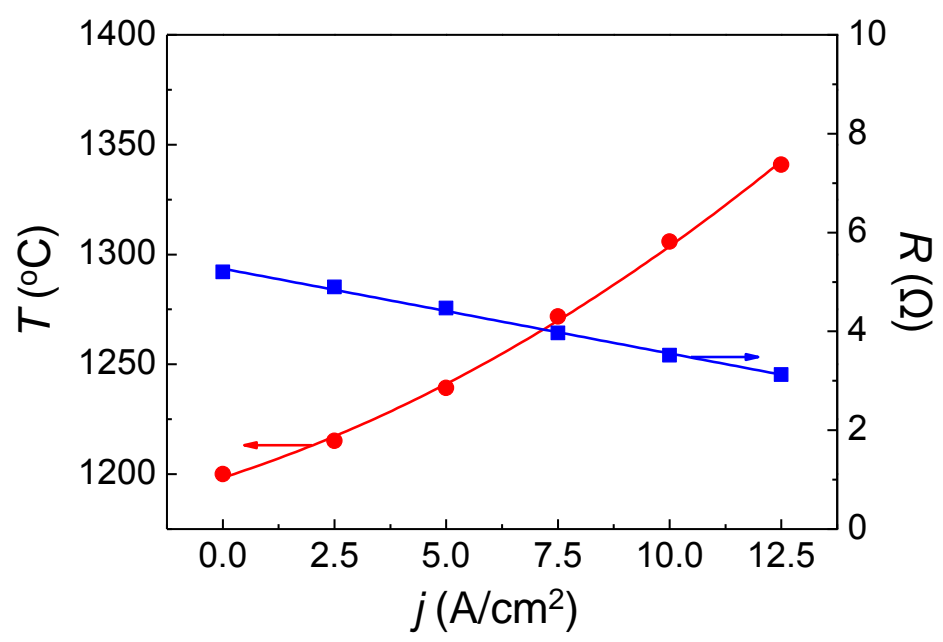


Figure 9 Resistance of the electrolyte (in blue) measured by impedance spectroscopy obtained under different DC current density $j$. Also shown are estimated sample temperatures (in red). Furnace temperature: $1200{ }^{\circ} \mathrm{C}$.

\subsection{Spatial Distribution of Defects and Equivalent Resistivity in Stoichiometric Oxides under a Temperature Gradient}

Thermal diffusion under a temperature gradient is a well-known phenomenon in a fluid (a liquid or a gas), where momentum and energy transfer from hotter to colder regions via collisions of Brownian molecules. In solids, a temperature gradient can change the chemical potential of charge carriers, shift their spatial distributions and create a voltage, known as Seebeck effect in thermoelectricity. In oxides, similar effect holds and here we shall consider stoichiometric $\mathrm{UO}_{2}$, which can be viewed as a wide bad-gap semiconductor, under a temperature gradient. The aim is to solve the spatial distributions of defects that contribute to electrical conduction at the temperature of interest, including electron e, hole h, fully ionized oxygen vacancy $\mathrm{V}_{\mathrm{O}}^{*}$ and oxygen interstitial $\mathrm{O}_{\mathrm{i}}^{\prime \prime}$, and estimate an averaged equivalent resistivity of a bulk sample. For simplicity, cation defects will not be considered because of their much lower concentrations and mobilities, which hardly contribute to any charge transport. (The formation and migration of cation defects are critical to the microstructural stability.) We shall start with one-dimension case and then extend to three-dimension case under cylindrical coordination.

The defect reactions are

$$
\begin{aligned}
& \text { nil }=\mathrm{e}+\mathrm{h} \\
& \begin{array}{l}
\mathrm{O}_{\mathrm{O}}^{\times}=\mathrm{V}_{\mathrm{O}}^{*}+\mathrm{O}_{\mathrm{i}}^{\prime \prime} \\
\quad \mathrm{O}_{\mathrm{O}}^{\times}=\mathrm{V}_{\mathrm{O}}^{*}+2 \mathrm{e}+\frac{1}{2} \mathrm{O}_{2}
\end{array}
\end{aligned}
$$

Using law of mass action, we have

$$
\begin{aligned}
& {[\mathrm{e}] \cdot[\mathrm{h}]=\exp \left(\frac{\Delta S_{1}}{k_{\mathrm{B}}}\right) \exp \left(-\frac{\Delta H_{1}}{k_{\mathrm{B}} T}\right)} \\
& \frac{\left[\mathrm{V}_{\mathrm{O}}^{*}\right] \cdot\left[\mathrm{O}_{\mathrm{i}}^{\prime \prime}\right]}{\left[\mathrm{O}_{\mathrm{O}}^{\times}\right]}=\exp \left(\frac{\Delta S_{2}}{k_{\mathrm{B}}}\right) \exp \left(-\frac{\Delta H_{2}}{k_{\mathrm{B}} T}\right) \\
& \frac{\left[\mathrm{V}_{\mathrm{O}}^{*}\right] \cdot[\mathrm{e}]^{2} \cdot\left[\mathrm{O}_{2}\right]^{\frac{1}{2}}}{\left[\mathrm{O}_{\mathrm{O}}^{\times}\right]}=\exp \left(\frac{\Delta S_{3}}{k_{\mathrm{B}}}\right) \exp \left(-\frac{\Delta H_{3}}{k_{\mathrm{B}} T}\right)
\end{aligned}
$$

where $\left(\Delta S_{1}, \Delta S_{2}, \Delta S_{3}\right)$ and $\left(\Delta H_{1}, \Delta H_{2}, \Delta H_{3}\right)$ are the entropy and enthalpy change of the defect reactions Eq. (1-3), respectively; $k_{\mathrm{B}}$ is the Boltzmann constant and $T$ is the temperature. To maintain charge neutrality, we have

$$
[\mathrm{e}]+2\left[\mathrm{O}_{\mathrm{i}}^{\prime \prime}\right]=[\mathrm{h}]+2\left[\mathrm{~V}_{\mathrm{O}}^{*}\right]
$$


If the thermodynamical data $\left(\Delta S_{1}, \Delta S_{2}, \Delta S_{3}\right)$ and ( $\left.\Delta H_{1}, \Delta H_{2}, \Delta H_{3}\right)$ are known, Eq. (4-7) relates the five unknowns, i.e. $[\mathrm{e}],[\mathrm{h}],\left[\mathrm{V}_{\mathrm{O}}^{*}\right],\left[\mathrm{O}_{\mathrm{i}}^{\prime \prime}\right]$, and oxygen partial pressure $\mathrm{PO}_{2}$ and leaves only one independent variable. We may then express $[\mathrm{e}],[\mathrm{h}],\left[\mathrm{V}_{\mathrm{O}}^{*}\right],\left[\mathrm{O}_{\mathrm{i}}^{\prime \prime}\right]$ as a function of (local) $\mathrm{PO}_{2}$, or alternatively express $[\mathrm{h}],\left[\mathrm{V}_{\mathrm{O}}^{*}\right],\left[\mathrm{O}_{\mathrm{i}}^{\prime \prime}\right]$ and $\mathrm{PO}_{2}$ as a function of $[\mathrm{e}]$.

The charge fluxes, $j_{\mathrm{O}^{2-}}$ for $\mathrm{O}^{2-}, j_{\mathrm{e}}$ for e and $j_{\mathrm{h}}$ for $\mathrm{h}$ can be written as

$$
\begin{gathered}
j_{\mathrm{O}^{2-}}=\frac{\sigma_{\mathrm{O}^{2-}}}{2 e} \nabla \tilde{\mu}_{\mathrm{O}^{2-}} \\
=\left(\left[\mathrm{V}_{\mathrm{O}}^{* *}\right] m_{\mathrm{V}_{\mathrm{o}}^{*}}+\left[\mathrm{O}_{\mathrm{i}}^{\prime \prime}\right] m_{\mathrm{O}_{\mathrm{i}}^{\prime \prime}}\right) \nabla\left(\mu_{\mathrm{O}^{2-}}^{\Theta}+k_{\mathrm{B}} T \ln \left[\mathrm{O}^{2-}\right]-2 e \phi\right) \\
=\left(\left[\mathrm{V}_{\mathrm{O}}^{*}\right] m_{\mathrm{V}_{\mathrm{o}}^{*}}+\left[\mathrm{O}_{\mathrm{i}}^{\prime \prime}\right] m_{\mathrm{O}_{\mathrm{i}}^{\prime \prime}}\right)\left\{\nabla\left(k_{\mathrm{B}} T \ln \left[\mathrm{O}^{2-}\right]\right)-2 e \nabla \phi\right\} \\
=\left(\left[\mathrm{V}_{\mathrm{O}}^{*}\right] m_{\mathrm{V}_{\mathrm{o}}^{*}}+\left[\mathrm{O}_{\mathrm{i}}^{\prime \prime}\right] m_{\mathrm{O}_{\mathrm{i}}^{\prime \prime}}\right)\left\{k_{\mathrm{B}} \ln \left[\mathrm{O}^{2-}\right] \nabla T+\frac{k_{\mathrm{B}} T}{\left[\mathrm{O}^{2-}\right]} \nabla\left[\mathrm{O}^{2-}\right]-2 e \nabla \phi\right\} \\
j_{\mathrm{e}}^{=}=\frac{\sigma_{\mathrm{e}}}{e} \nabla \tilde{\mu}_{\mathrm{e}} \\
=[\mathrm{e}] m_{\mathrm{e}} \nabla\left(\mu_{\mathrm{e}}^{\Theta}+k_{\mathrm{B}} T \ln [\mathrm{e}]-e \phi\right) \\
=[\mathrm{e}] m_{\mathrm{e}}\left\{k_{\mathrm{B}} \ln [\mathrm{e}] \nabla T+\frac{k_{\mathrm{B}} T}{[\mathrm{e}]} \nabla[\mathrm{e}]-e \nabla \phi\right\} \\
j_{\mathrm{h}}=-\frac{\sigma_{\mathrm{h}}}{e} \nabla \tilde{\mu}_{\mathrm{h}} \\
=-[\mathrm{h}] m_{\mathrm{h}} \nabla\left(\mu_{\mathrm{h}}^{\Theta}+k_{\mathrm{B}} T \ln [\mathrm{h}]+e \phi\right) \\
=-[\mathrm{h}] m_{\mathrm{h}}\left\{k_{\mathrm{B}} \ln [\mathrm{h}] \nabla T+\frac{k_{\mathrm{B}} T}{[\mathrm{~h}]} \nabla[\mathrm{h}]+e \nabla \phi\right\}
\end{gathered}
$$

where $\sigma_{i}$ is the conductivity, $m_{i}$ is the mobility, $\tilde{\mu}_{i}$ is the electrochemical potential, $\mu_{0^{2}}^{\Theta}$ is the chemical potential at standard condition, of species $i ; \phi$ is the electrostatic potential. At steady state, there is no net transport of mass and charge. Hence,

$$
\begin{aligned}
& j_{\mathrm{O}^{2-}}=0 \\
& j_{\mathrm{e}}+j_{\mathrm{h}}=0
\end{aligned}
$$

If the concentrations of ionic defects are dilute, i.e. $\left[\mathrm{V}_{\mathrm{O}}^{*}\right] \ll<1,\left[\mathrm{O}_{\mathrm{i}}^{\prime \prime}\right]<<1$, so that $\left[\mathrm{O}^{2-}\right] \approx 1$ is maintained across the thermodynamical conditions of interest, Eq. (8) reduces to

$$
j_{\mathrm{O}^{2-}}=\left(\left[\mathrm{V}_{\mathrm{O}}^{*}\right] m_{\mathrm{V}_{\mathrm{o}}^{*}}+\left[\mathrm{O}_{\mathrm{i}}^{\prime \prime}\right] m_{\mathrm{O}^{\prime \prime}}\right)\{-2 e \nabla \phi\}
$$

Then, Eq. (11) gives

$$
\nabla \phi=0
$$

Eq. (12) can be re-written as 


$$
\begin{gathered}
{[\mathrm{e}] m_{\mathrm{e}}\left\{k_{\mathrm{B}} \ln [\mathrm{e}] \nabla T+\frac{k_{\mathrm{B}} T}{[\mathrm{e}]} \nabla[\mathrm{e}]\right\}-[\mathrm{h}] m_{\mathrm{h}}\left\{k_{\mathrm{B}} \ln [\mathrm{h}] \nabla T+\frac{k_{\mathrm{B}} T}{[\mathrm{~h}]} \nabla[\mathrm{h}]\right\}=0} \\
\left\{m_{\mathrm{e}}[\mathrm{e}] \ln [\mathrm{e}]-m_{\mathrm{h}}[\mathrm{h}] \ln [\mathrm{h}]\right\} \nabla T+m_{\mathrm{e}} T \nabla[\mathrm{e}]-m_{\mathrm{h}} T \nabla[\mathrm{h}]=0
\end{gathered}
$$

Since $[\mathrm{h}]$ is already a known function of [e] and $T$ according to Eq. (4), the left hand side of Eq. (16) is a function of [e] only and can now be solved. After obtaining the spatial distribution of $[\mathrm{e}]$, the profile of $[\mathrm{h}],\left[\mathrm{V}_{\mathrm{O}}^{*}\right],\left[\mathrm{O}_{\mathrm{i}}^{\prime \prime}\right]$ and $\mathrm{PO}_{2}$ can be solved using Eq. (4-7). This completes our solutions here.

Below we shall provide some numerical solutions to the above problem. For convenience, we rewrite Eq. (16) as

$$
\begin{gathered}
\left\{m_{\mathrm{e}}[\mathrm{e}] \ln [\mathrm{e}]-m_{\mathrm{h}}[\mathrm{h}] \ln [\mathrm{h}]\right\} \nabla T+T\left(m_{\mathrm{e}}+\frac{[\mathrm{h}]}{[\mathrm{e}]} m_{\mathrm{h}}\right) \nabla[\mathrm{e}]-m_{h} \frac{\Delta H_{1}}{k_{\mathrm{B}} T}[\mathrm{~h}] \nabla T=0 \\
T\left(\frac{m_{\mathrm{e}}}{m_{\mathrm{h}}}+\frac{[\mathrm{h}]}{[\mathrm{e}]}\right) \nabla[\mathrm{e}]=\frac{\Delta H_{1}}{k_{\mathrm{B}} T}[\mathrm{~h}] \nabla T-\left\{\frac{m_{\mathrm{e}}}{m_{\mathrm{h}}}[\mathrm{e}] \ln [\mathrm{e}]-[\mathrm{h}] \ln [\mathrm{h}]\right\} \nabla T
\end{gathered}
$$

We shall consider a one-dimensional problem along $x$-axis ranging from 0 to $6 \mathrm{~mm}$, with a parabolic temperature profile of $2000^{\circ} \mathrm{C}$ in the center ( $x=3$; representing the core of the fuel) and $600{ }^{\circ} \mathrm{C}$ at the two boundaries ( $x=0$ and 6; representing the surfaces of the fuel). For reaction (1), we use $\Delta S_{1}=2 k_{\mathrm{B}}$ and $\Delta H_{1}=2 \mathrm{eV}$ (Winter, P. W. "The electronic transport properties of $\mathrm{UO}_{2} . "$ Journal of Nuclear Materials 161.1 (1989): 38-43.) We assume at the surfaces of the fuel, $\mathrm{UO}_{2}$ maintains its stoichiometry so that $[\mathrm{e}]=[\mathrm{h}]$. The mobility ratio $\frac{m_{\mathrm{e}}}{m_{\mathrm{h}}}$ between electrons and holes will be the variable. Interestingly, we will show that the fuel could change its stoichiometry (becoming $\mathrm{UO}_{2 \pm \delta}$ ) simply because of the temperature gradient (without irradiation!) as long as the mobility ratio is exactly a unity. The numerical solutions are plotted in Figure 10, where Figure 10a shows the temperature profiles and Figure 10b-f show the spatial distributions of the electron and hole concentrations at various $\frac{m_{\mathrm{e}}}{m_{\mathrm{h}}}$. From Figure 10b, it is clear when electron and hole have the same mobility, $\mathrm{UO}_{2}$ is stoichiometry and $[\mathrm{e}]=[\mathrm{h}]$. When electron mobility is higher than hole mobility, as is the case in Figure $10 \mathrm{c}-\mathrm{d}$, with the boundary condition met, $[\mathrm{e}]<[\mathrm{h}]$ in the bulk and the fuel is overstoichiometric in the form of $\mathrm{UO}_{2+\delta}$. Similarly, when electron mobility is higher than hole mobility, as is the case in Figure 10 e-f, with the boundary condition met, $[\mathrm{e}]>[\mathrm{h}]$ in the bulk and the fuel is overstoichiometric in the form of $\mathrm{UO}_{2-\delta}$. 
(a)

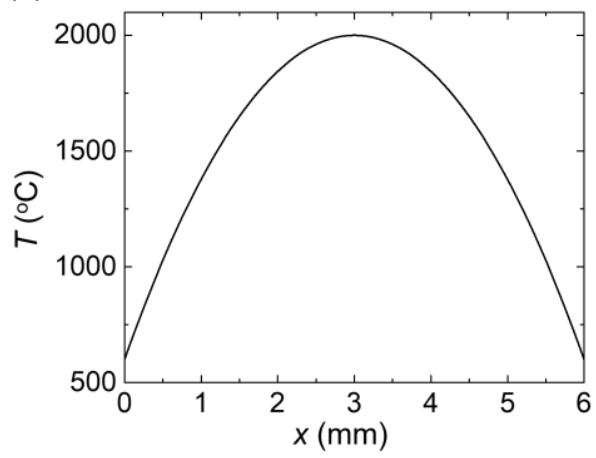

(c)

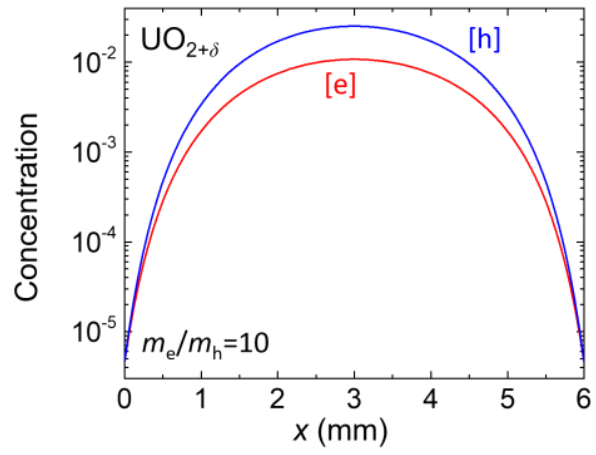

(e)

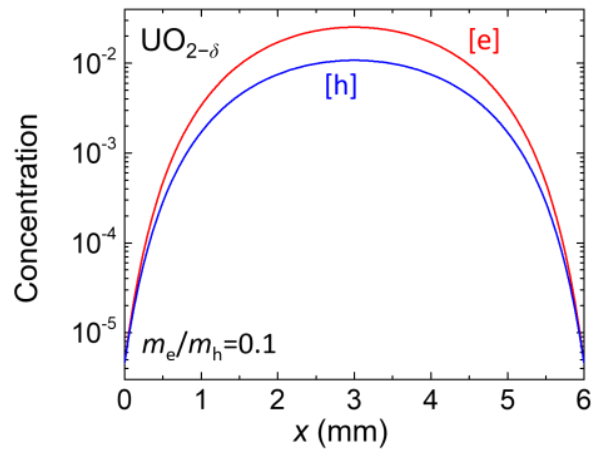

(b)

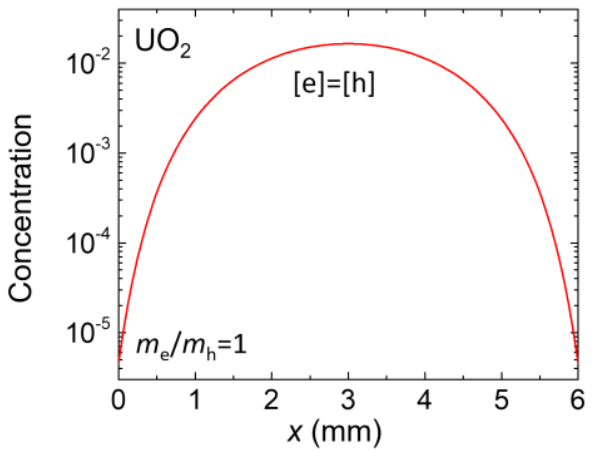

(d)

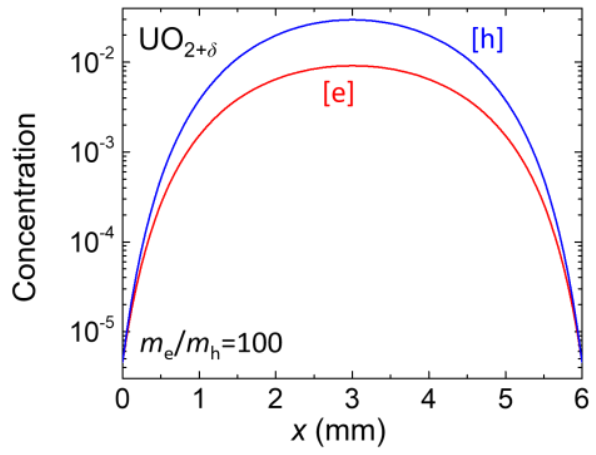

(f)

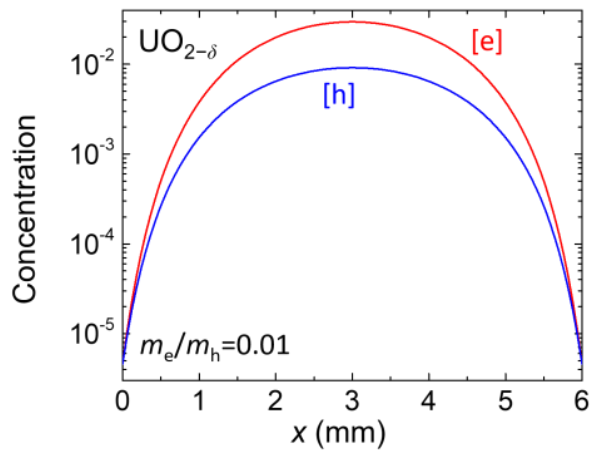

Figure 10. Fuel stoichiometry changing with temperature gradient at various mobility ratio $\left(\mathrm{m}_{\mathrm{e}} / \mathrm{m}_{\mathrm{h}}\right)$ 


\section{Electrochemical Impedance Systems Setup and Measurement}

\subsection{Experimental System Setup}

The setup of the EIS experimental system started from last quarter and has been completed in this quarter. The setup process includes Laboratory Instruction (LI) approval, conceptual experimental process design, equipment purchasing, and facility assembling. The LI for this project went through the following steps for final approval: drafting, review process, project meeting, final walk through, and approval. Various risks are identified and corresponding controls (Engineering and Administrative Controls) are explored for conducting the experiment in this LI. In addition, some pre-required trainings were finished including 00INL72P INL Radworker 1, 00INL670 Lab Access Training, 0INL1491 Laboratory Ergonomics, 000INL13 Chemical Hygiene, 0INL1041 Compressed Gas Safety, SMJS992B, Flammable/Combustible, QN000PSA: Pressure System Assembler, IGET0000 INL General Employee Access.

The conceptual design for the experimental system is as shown in Figure 11 and 12, which was described in last milestone report. A brief description is as following. The tube systems in Figure 11 and 12 are same outside the furnace, while the reactor figuration inside the furnace is different. According to the conceptual design, the actual experimental system for EIS measurement is shown as Figure 13.

The system in Figure 11 is to provide uniform gas pressure for the testing sample, while the system in Figure 12 can control gas pressure separately for both sides of the sample. Taking Figure 11 as an example to describe the process flow from inside to outside. The reactor is a 2" OD process tube setting inside a split Tube Furnace, which can be up to $1500^{\circ} \mathrm{C}$. The pellet oxide is mounted inside the reactor and its impedance will be measured at different temperature $\left(800-1200^{\circ} \mathrm{C}\right)$ and different oxygen partial pressure $\left(10^{-25}-1 \mathrm{~atm}\right)$. Various temperatures will be obtained by controlling the furnace. The hydrogen concentration in the whole system is always lower than $0.1 \%$.

Different oxygen partial pressure will be achieved through gases mixing or water vapor dissociation. Oxygen and nitrogen connected to provide higher oxygen partial pressure $\left(10^{-3}-1\right.$ atm) by adjusting the $\mathrm{N}_{2} / \mathrm{O}_{2}$ mixing ratio through mass flow controllers. Low $\mathrm{P}_{\mathrm{O} 2}\left(10^{-25}-10^{-15}\right.$ atm) are generated by varying the $\mathrm{H}_{2} / \mathrm{N}_{2}$ ratio at a constant water vapor pressure of $2 \times 10^{-4} \mathrm{~atm}$. The constant water vapor pressure is maintained by a water bubbler, where the $\mathrm{H}_{2} / \mathrm{N}_{2}$ mixture goes through. The $\mathrm{P}_{\mathrm{O} 2}$ is calculated from the $\mathrm{P}_{\mathrm{H} 2}, \mathrm{P}_{\mathrm{H} 2 \mathrm{O}}$ and the equilibrium constant for water vapor dissociation at the measurement temperature. 
Since the system in Figure 11 is to provide uniform pressure for the sample, the shut off valve \#3 and 4, and three-way valve 1 are always closed, which are only for separately controlled gas. When operating at high $\mathrm{P}_{\mathrm{O} 2}$ as shown in Figure 11.1, oxygen and nitrogen \#1 cylinders are open, while $3 \%$ hydrogen cylinder and nitrogen \#2 are closed. Shut off valve \#1 and 2 are open, while shut off valve \#5 is closed. And the three-way valve \#2 facing the hydrogen side is closed, only oxygen and nitrogen is going through the pipes to feed in.

When operating at lower $\mathrm{P}_{\mathrm{O} 2}$ as shown in Figure 11.2, oxygen and nitrogen \#1 cylinders are closed, while 3\% hydrogen cylinder and nitrogen \#2 are open. Shut off valve \#1 and 2 are closed, while shut off valve \#5 is open. And the three-way valve \#2 facing the oxygen side is closed, only hydrogen and nitrogen is going through the pipes to feed in.

During operation, oxygen and hydrogen gas will not be used at the same time. Between each experiment with different oxygen pressure, the pipes are flushed by pure nitrogen to remove previous oxygen residues.

If the off gas temperature exiting from the furnace is higher than $50^{\circ} \mathrm{C}$, the gases are passed through a water cooling jacket to reduce temperature to lower than $50^{\circ} \mathrm{C}$. After passing through the cooling jacket gases will be vented to the hood. A provision to capture a small volume of gas ( $<1$ Liter) into a Tedlar bag for transport for GC analysis in another laboratory. Vented gases will contain lower than $0.1 \%$ hydrogen.

Figure 12 shows the tube system for separately controlled oxygen pressure for each side of pellet samples. The sample will be mounted at the end of a smaller (about 3/8") ceramic tube, and is gas tight. Then the gas pressure for the outside and inside of the smaller tube can be controlled separately. For example, in order to achieve high $\mathrm{P}_{\mathrm{O} 2}$ for the outside of the pellet sample, while low pressure for the inside, the following procedure will be followed as shown in Figure 12.1: all the four gas cylinders are open; for oxygen side, shut off valve \#1, 3 are open, while valve \#2 is closed. The three-way valve \#1 facing the hydrogen side is closed, only oxygen is going through the pipes to feed in. For the hydrogen side, the shut valve \#5 is open, while valve \#4 is closed. The three-way valve \#2 facing the oxygen side is closed, only hydrogen is going through the pipes to feed in.

On the other hand, in order to achieve low $\mathrm{P}_{\mathrm{O} 2}$ for the outside of the pellet sample, while high pressure for the inside, the following procedure will be followed as shown in Figure 12.2: all the four gas cylinders are open; for oxygen side, shut off valve \#1, 2 are open, while valve \#3 is closed. The three-way valve \#2 facing the hydrogen side is closed, only oxygen is going through the pipes to feed in. For the hydrogen side, the shut valve \#4 is open, while valve \#5 is closed. The three-way valve \#1 facing the oxygen side is closed, only hydrogen is going through the pipes to feed in. 
The system in Figure 12 will be used to investigate hydride formation of zirconium-based alloys. $\mathrm{BaCeO}_{3}$ or other proton conduction oxides are coated on each side of the pellet for form an electrochemical cell. The coating process will be formed by applying Pt paste to the surfaces of the pellet samples and firing at $1500{ }^{\circ} \mathrm{C}$ for $4 \mathrm{~h}$ in oxygen in a hood. The gas pressure at each side can be adjusted separately controlled. The oxygen pressure is less than $2 \mathrm{~atm}$ on both sides.

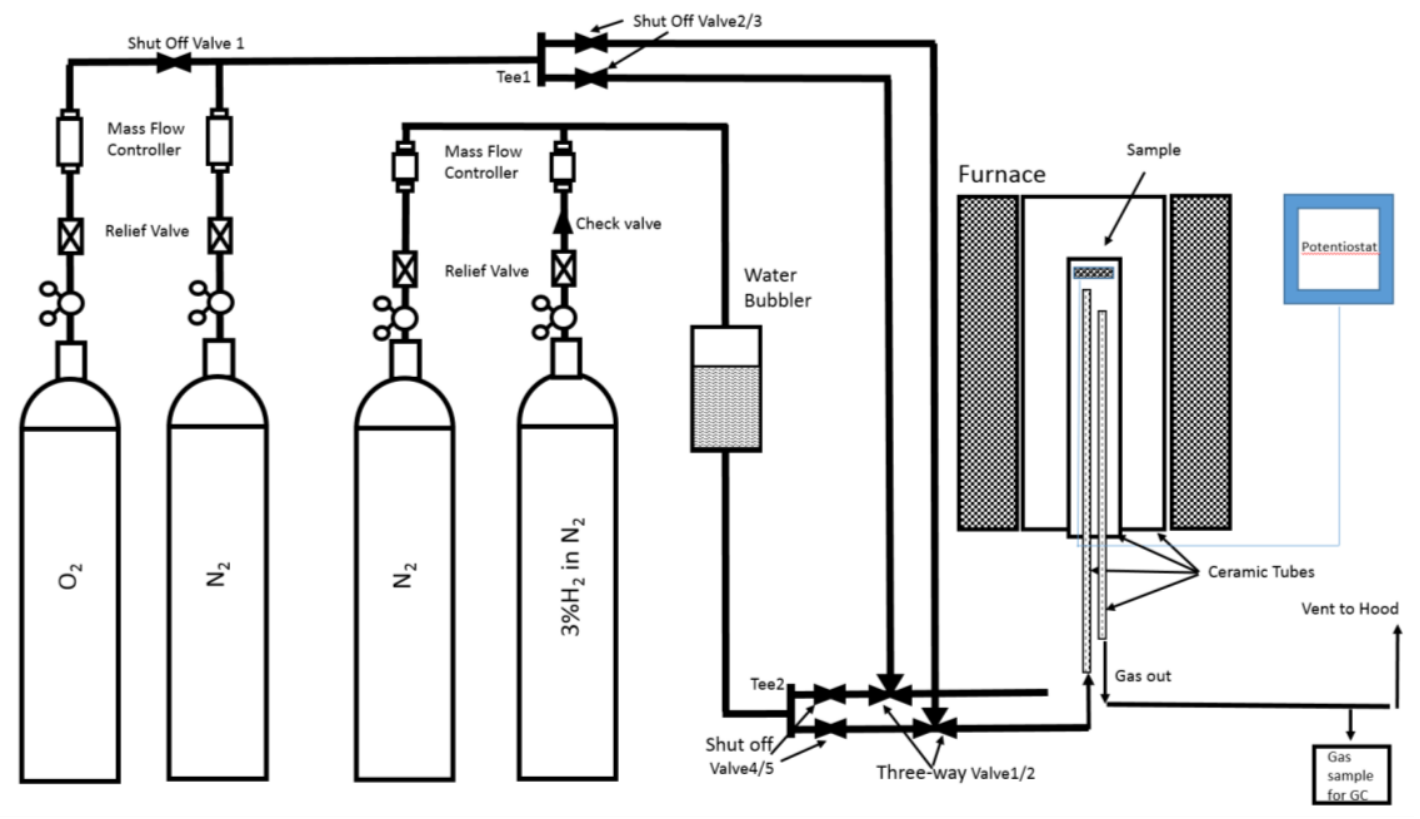

Figure 11. Original instrumentation diagram at uniform pressure 


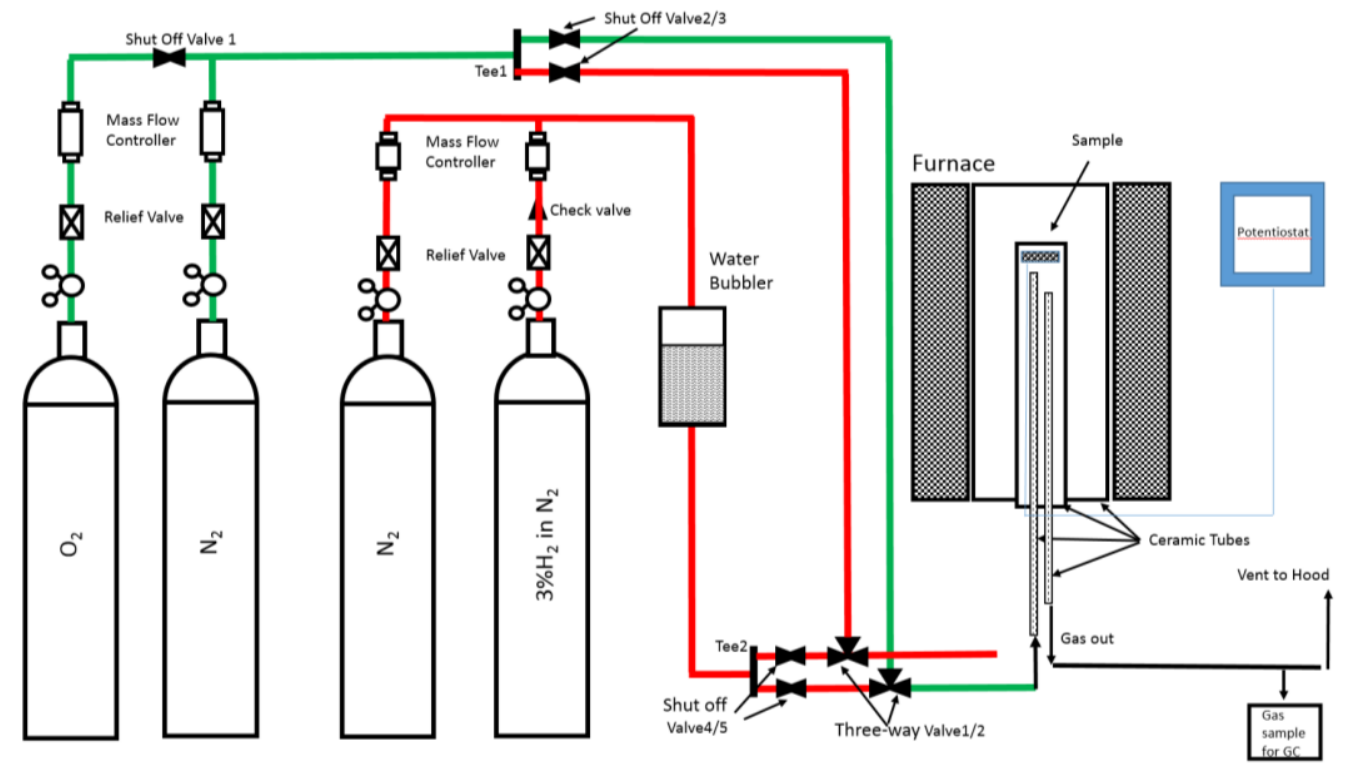

Figure 11.1. Gas flow diagram for high $\mathrm{P}_{\mathrm{O} 2}$ flow at uniform pressure

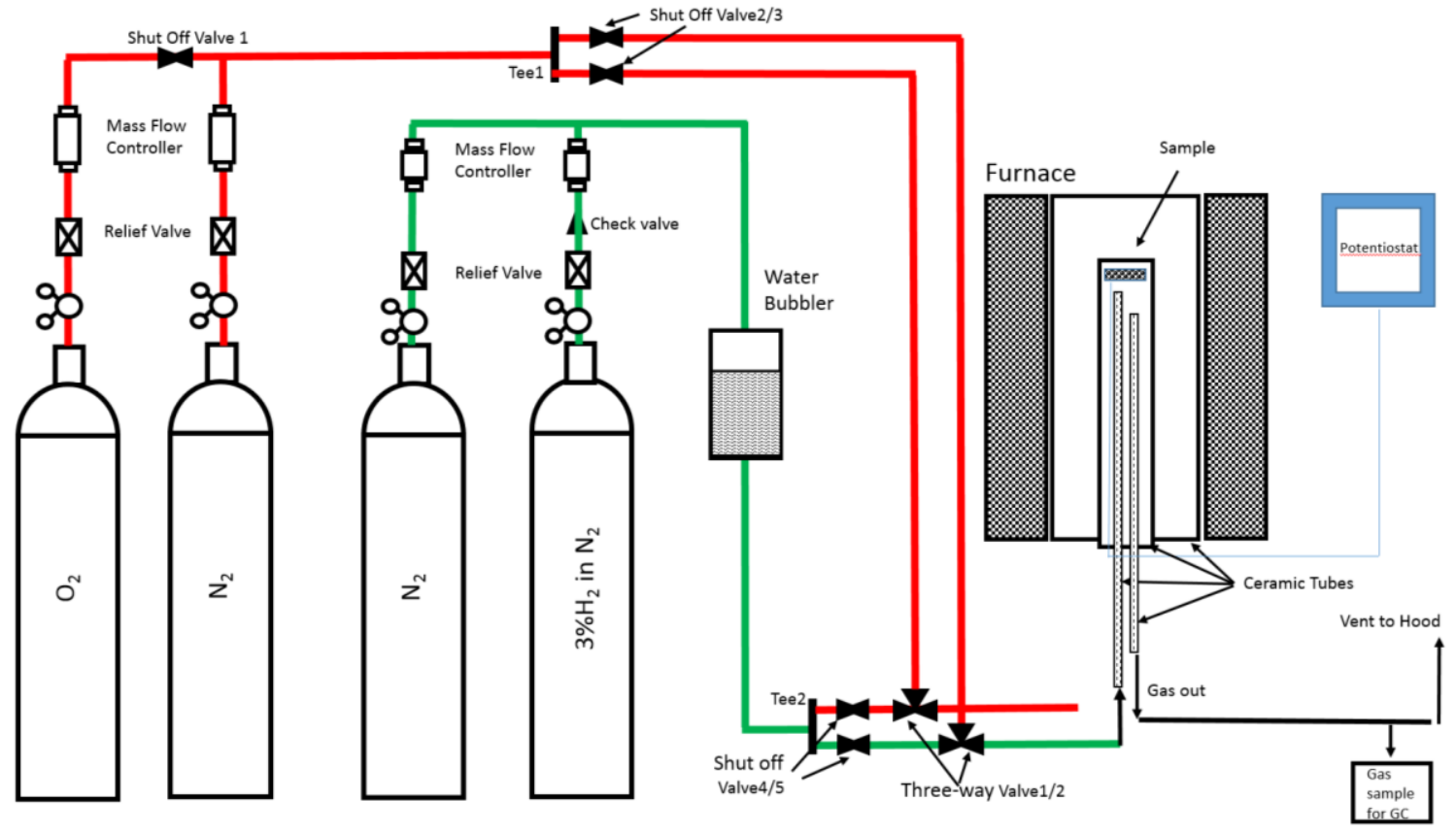

Figure 11.2. Gas flow diagram for low $\mathrm{P}_{\mathrm{O} 2}$ flow at uniform pressure 


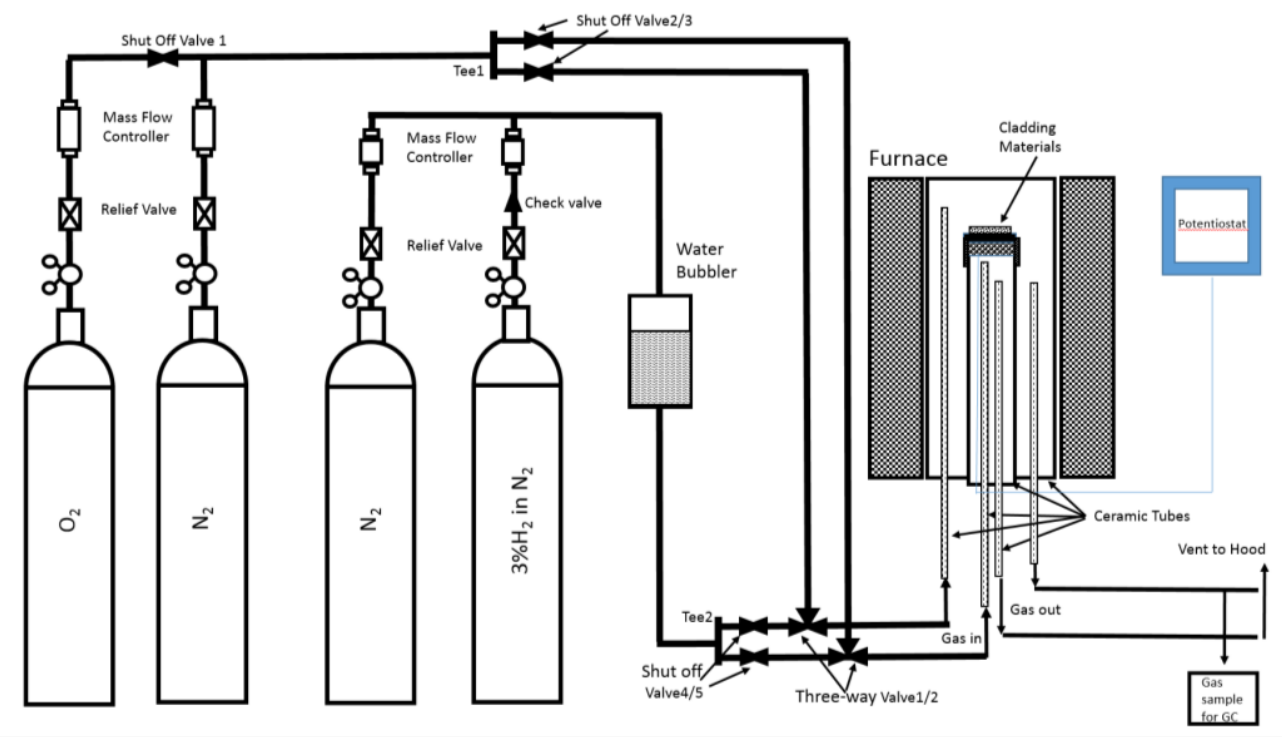

Figure 12. Original instrumentation diagram for separately controlled pressure on two sides of a sample

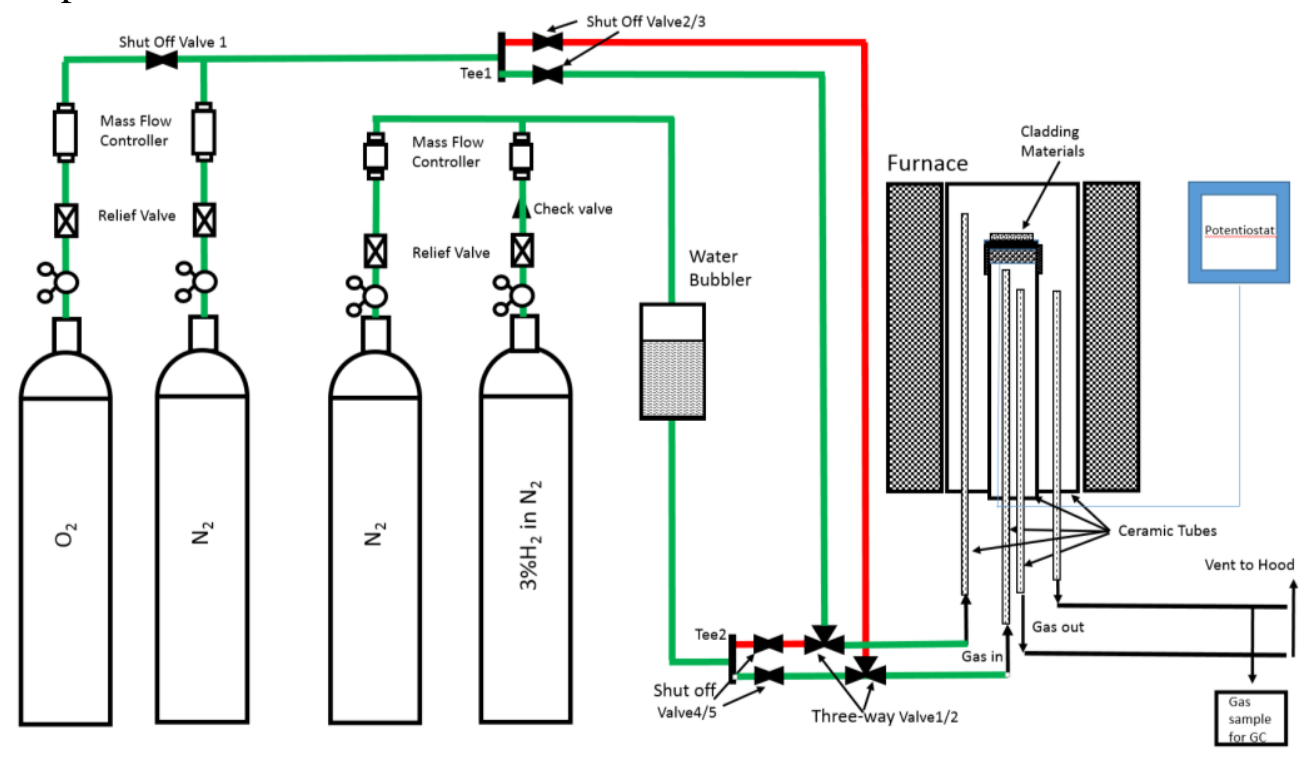

Figure 12.1. Gas flow diagram for high $\mathrm{P}_{\mathrm{O} 2}$ for outside, while low pressure for inside of the sample 


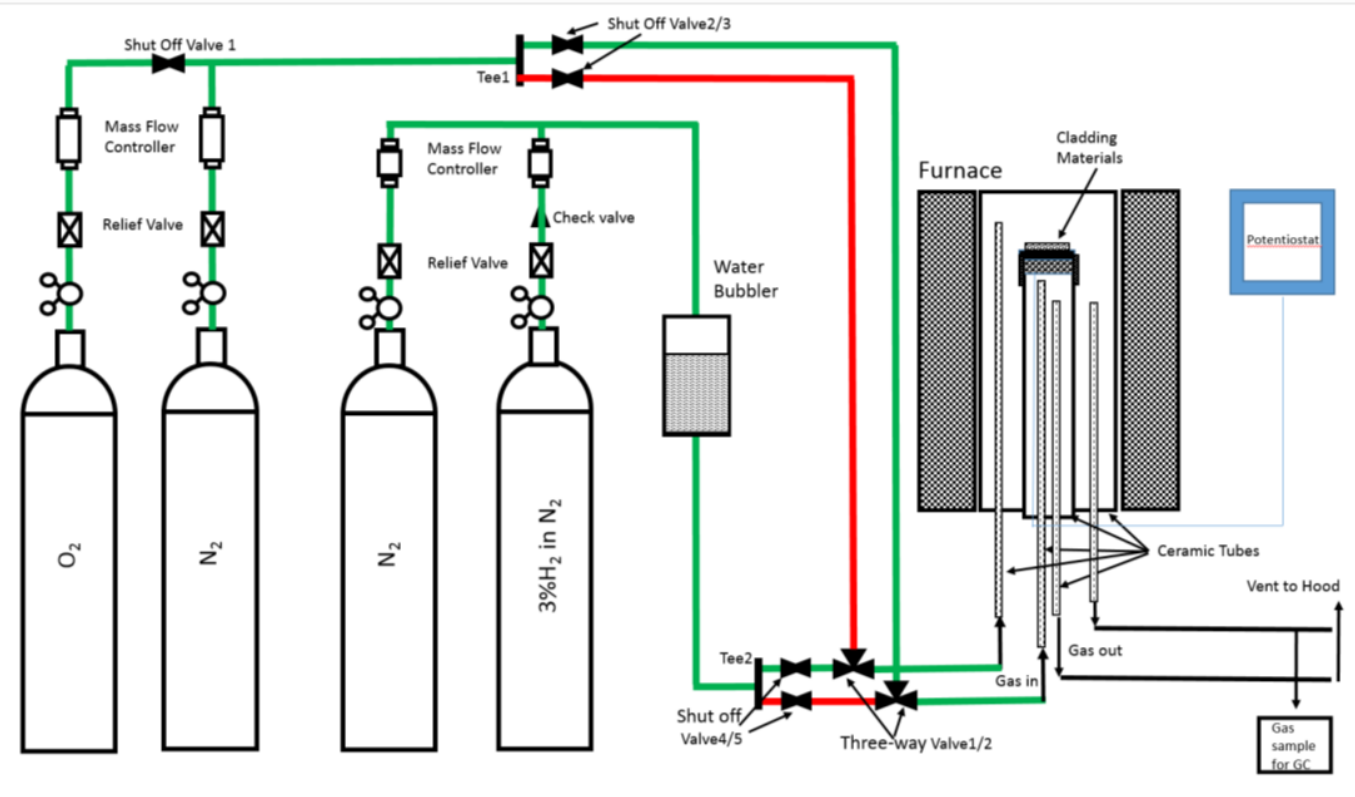

Figure 12.2. Gas flow diagram for low $\mathrm{P}_{\mathrm{O} 2}$ for outside, while high pressure for inside of the sample 

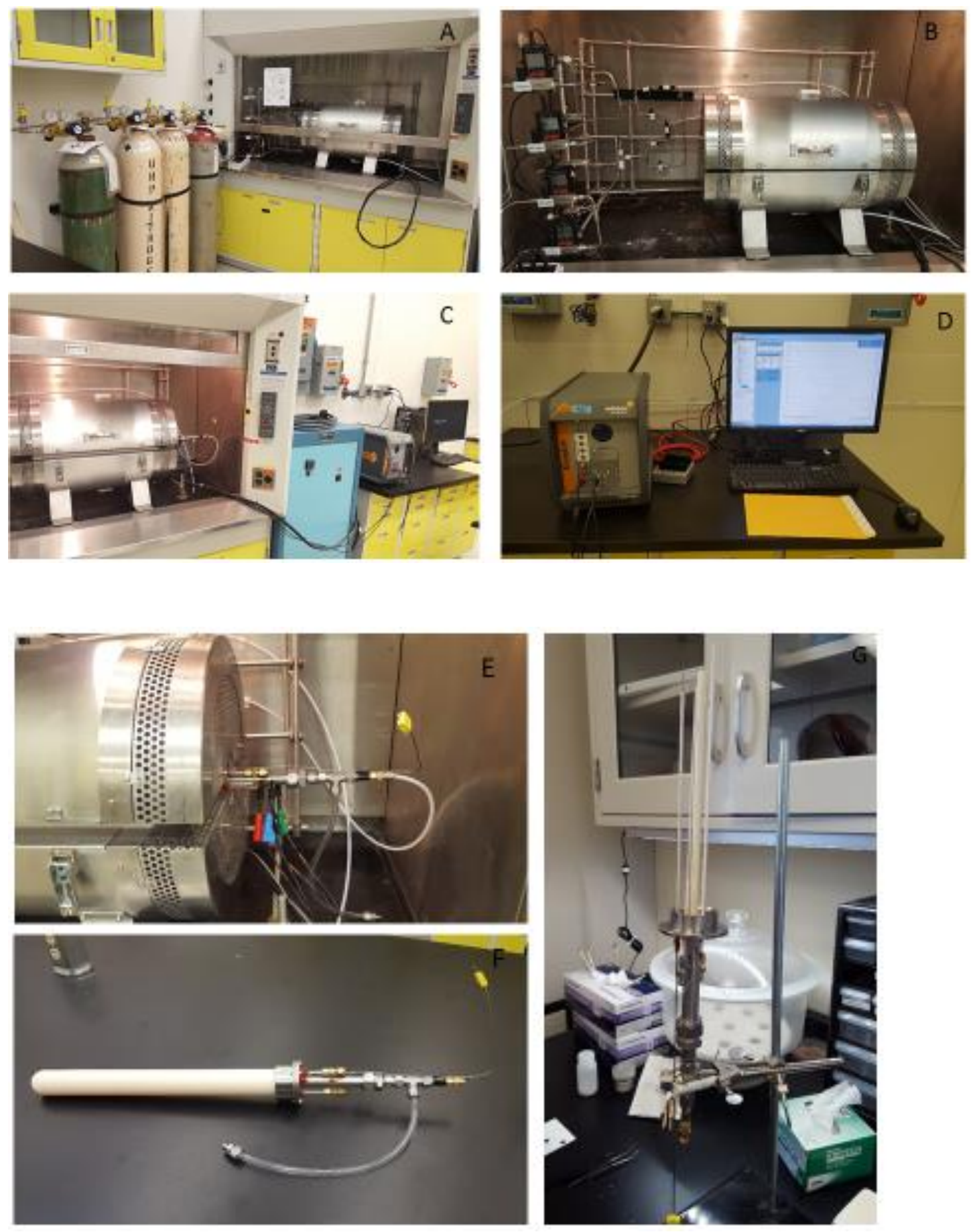

Figure 13. EIS experimental system: tubes connecting gas cylinders $\left(\mathrm{O}_{2}, \mathrm{~N}_{2}, \mathrm{~N}_{2}\right.$ and $3 \% \mathrm{H}_{2}$ in $\mathrm{N}_{2}$ for cylinder \#1-4) with furnace (A and B); furnace with its power source $(\mathrm{C})$; potentiostat for EIS measurement (D); ceramic tube reactor placing inside the furnace (E and F); internal design of the tube reactor $(\mathrm{G})$. 


\subsection{Method for Conductivity Measurement}

Ceria $\left(\mathrm{CeO}_{2}\right)$ and $\mathrm{BaCeO}_{3}$ are selected as the surrogate oxide samples for EIS measurement due to their unique characteristics. Ceria is often used as a surrogate for $\mathrm{UO}_{2}, \mathrm{PuO}_{2}$ and a representative ceramic for spent fuel $\mathrm{UO}_{2}$ pellets for studying the material properties of the fuel oxides, since ceria possesses identical structure and has similar thermophysical properties such as density and melting point (He et al., 2013). It is much easier, safer, and far less expensive to conduct as many tests as possible using non-radioactive, then slightly radioactive surrogates than radioactive fuels.

$\mathrm{BaCeO}_{3}$ belongs to a group of high temperature protonic conductors in moist atmosphere when doped with trivalent cations such as $\mathrm{Y}^{3+}$ and $\mathrm{Gd}^{3+}$ (Tyagi and Banerjee. 2017; Kreuer et al., 1996). Its non-stoichiometry in the compound can be varied by equilibrating under well defined oxygen partial pressure at high temperatures or by doping with trivalent cations (He et al., 1997; Kreuer et al., 1996).

Ceria pellets were prepared using as-received powders (GDC10-TC, Nexceris, LLC., OH) with a sintering condition of $1300^{\circ} \mathrm{C}$ for 6 hour and ramping/cooling rate of $5{ }^{\circ} \mathrm{C} / \mathrm{min}$. The dimension of obtained pellets are about $8.5 \mathrm{~mm}$ ID by $1 \mathrm{~mm}$ thickness. The rim of a pellet was grooved at $90^{\circ}$ intervals and four Pt wires of thickness $0.25 \mathrm{~mm}$ are used to connect pellet samples with the impedance spectroscopy instrument. Electrical contacts will be formed by applying Pt paste to the surfaces of the pellet samples and firing at $1500{ }^{\circ} \mathrm{C}$ for $4 \mathrm{~h}$ in oxygen. The impedance spectra is to be recorded in the frequency range between $0.1 \mathrm{~Hz}$ and $1 \mathrm{MHz}$ at an applied signal of 200 $\mathrm{mV}$, which will used for calculation of conductivity.

Before measurements are accepted, the phase angle of the impedance is automatically checked to ensure that it is below $2^{\circ}$. Resistance are converted to conductivities in post experiment data analysis using related equations. When the gas composition is changed readings stabilized after 20 min in $\mathrm{N}_{2} / \mathrm{O}_{2}\left(1-2 \mathrm{~h}\right.$ in $\left.\mathrm{H}_{2} / \mathrm{N}_{2}\right)$, thereafter becoming repeatable to the third decimal figure.

The total conductivity can be expressed by the following equation from point defect model (He et al., 1997; Bonanos 1993);

$\sigma_{\mathrm{t}}=\sigma_{\mathrm{i}}+\sigma_{\mathrm{p}}^{0}\left(\mathrm{P}_{\mathrm{O} 2}\right)^{1 / 4}+\sigma_{\mathrm{n}}^{0}\left(\mathrm{P}_{\mathrm{O} 2}\right)^{-1 / 4}$

where, $\sigma_{\mathrm{i}}, \sigma_{\mathrm{n}}, \sigma_{\mathrm{p}}$ represent the ionic, p-type (electron holes) and n-type (electrons) contributions.

If each conductivity component is thermally activated, the Eq.(19) can be written as following Eq. (20) to describe the temperature- and P,-dependence of the total conductivity: 
$\sigma_{\mathrm{t}}=\mathrm{A}_{\mathrm{i}} \exp \left(-\Delta \mathrm{H}_{\mathrm{i}} / \mathrm{kT}\right)+\left[\mathrm{A}_{\mathrm{i}} \exp \left(-\Delta \mathrm{H}_{\mathrm{i}} / \mathrm{kT}\right)\right]\left(\mathrm{P}_{\mathrm{O} 2}\right)^{1 / 4}+\left[\mathrm{A}_{\mathrm{i}} \exp \left(-\Delta \mathrm{H}_{\mathrm{i}} / \mathrm{kT}\right)\right]\left(\mathrm{P}_{\mathrm{O} 2}\right)^{-1 / 4}$

The van der Pauw technique was used in order to measure conductivity by attaching four leads to the measured sample. The current is applied via two adjacent ones, A, B, and voltage is measured via the other two, $\mathrm{C}, \mathrm{D}$. This gives the resistance $\mathrm{R}_{\mathrm{AB}}$, DC. Leads $\mathrm{A}$ and $\mathrm{C}$ are then interchanged and the resistance $\mathrm{R}_{\mathrm{CB}}$, DA is determined. The two resistances, the sample thickness, $\mathrm{d}$, and the conductivity, $\sigma$, are related as follows:

$\exp \left(-\pi \mathrm{d} \sigma \mathrm{R}_{\mathrm{AB}, \mathrm{DC}}\right)+\exp \left(-\pi \mathrm{d} \sigma \mathrm{R}_{\mathrm{CB}, \mathrm{DA}}\right)=1$

If leads were put equally spaced on a circular pellet, then $\mathrm{R}_{\mathrm{AB}, \mathrm{DC}}=\mathrm{R}_{\mathrm{CB}}$, DA . Then $\sigma$ can be obtained as:

$\sigma=\ln (2) /\left(\pi \mathrm{d} \mathrm{R}_{\mathrm{CB}, \mathrm{DA}}\right)$

From the analysis of the impedance data, the resistance of the pellet is extracted from the high frequency semicircle. Then the bulk conductivity is calculated from Eq. 22. Due to limitations, the $\mathrm{CeO}_{2}$ pellet was investigated at $800{ }^{\circ} \mathrm{C}$ at different oxygen partial as shown in Figure 14 with solid line showing conductivity isotherms fitted to Eq. 19. The conductivity data indicate a hole conduction at high oxygen partial pressures, an electron conduction at low oxygen partial pressures as well as a $p_{02}$ independent ionic conduction region at intermediate oxygen partial pressures. The solid red line is fitted with Eq. 19 following the point defect model, where indicates the three contribution from ionic, electrons and electron holes to the total conductivity. This trend may be clearer at higher temperature testing.

This observation is in good agreement with the data of $\mathrm{Gd}$-doped $\mathrm{BaCeO}$ as shown in Figure 15 (Bonanos 1993; He et al., 1997), where the samples were tested at wide range of temperature from $800{ }^{\circ} \mathrm{C}$ to $1200{ }^{\circ} \mathrm{C}$. At higher temperature (e.g., $1200{ }^{\circ} \mathrm{C}$ ), it is clearly demonstrated three contributions: a hole conduction at high oxygen partial pressures, an electron conduction at low oxygen partial pressures, and a $\mathrm{p}_{\mathrm{o} 2}$ independent ionic conduction region at intermediate oxygen partial pressures. 


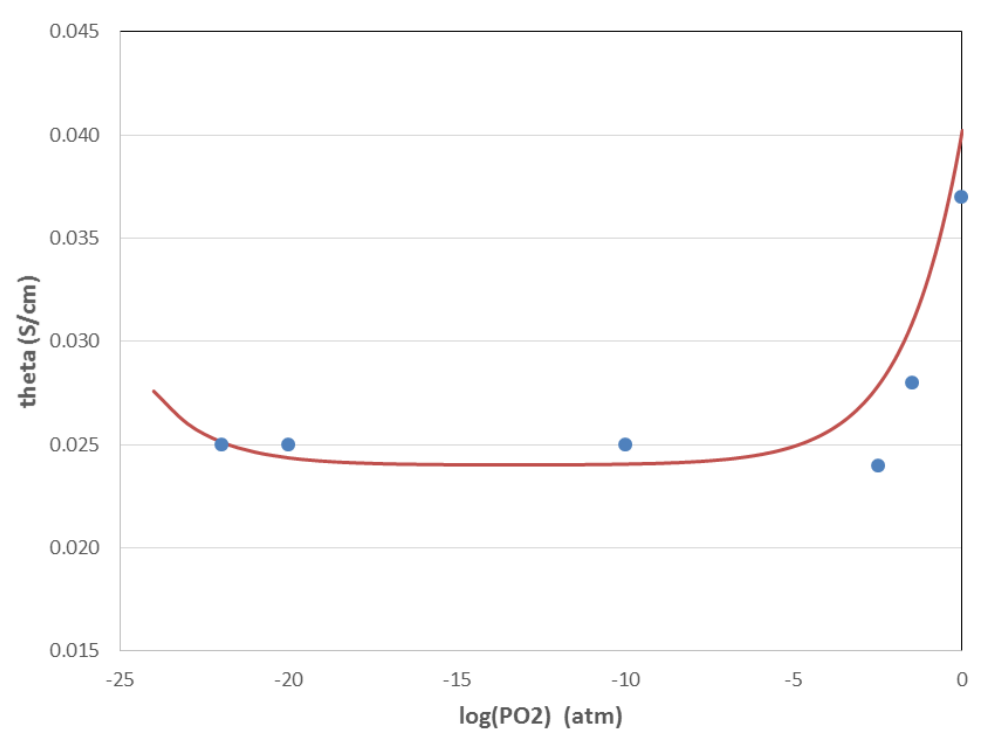

Figure 14. Electrical conductivities of $\mathrm{CeO}_{2}$ as a function of oxygen partial pressure at $800{ }^{\circ} \mathrm{C}$. The solid line is fitted by the defect model of Eq. 19.

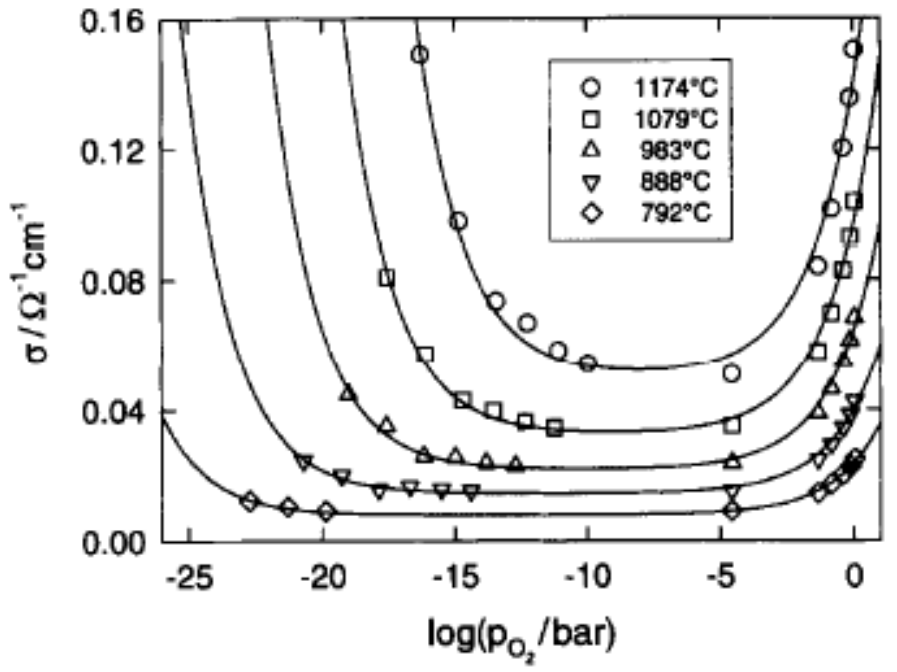

Figure 15. Electrical conductivities of $\mathrm{Gd}$-doped $\mathrm{BaCeO}_{3}$ as a function of oxygen partial pressure in the temperature region between $800{ }^{\circ} \mathrm{C}$ and $1200{ }^{\circ} \mathrm{C}$. (Adapted from He at el., 1997) 


\section{Establishing Capability of Advanced Characterization}

\section{Establishment of high temperature Raman characterization capability:}

A Raman spectrum obtained from the surface of a Raman-active sample can be used to qualitatively determine material composition, stoichiometry, order-disorder, elastic strain, and plastic deformation. Spatially resolved Raman spectra could be obtained for the surface of interest by appropriate choice of laser wavelength and microscope objective. To study the $e x$-situ surface chemical changes (e,g, oxide and hydride formation) to Zircaloy-based cladding and oxide fuel materials, a Horiba LabRAM HR Evolution Raman microscope with a 532nm laser source and submicron spot size and spatially mapping capability at BSU is leveraged. Preliminary experimental work was conducted (Figure 1) to establish Raman characterization proficiency of $\mathrm{CeO}_{2}$ fuel surrogates and $\mathrm{Zr}$-alloy cladding materials and capture and identify Raman spectra associated with relevant $\mathrm{Ce}-\mathrm{O}$ and $\mathrm{Zr}-\mathrm{O}$ bond shifts. Conducted at ambient temperature these results establish the baseline for comparison with high temperature data through similar analysis procedures. This is the first time these measurements have been performed at BSU and provide confidence in the viability of this effort.

A Herrick High Temperature Reaction Chamber was purchased to enable high-temp Raman up to $910^{\circ} \mathrm{C}$ with environmental control to be implemented. This stage has been procured and recently set-up, initial high temp Raman experiments are currently underway. This experimental capability will allow the correlation of high temperature EIS data (conducted by the INL lead) with chemical changes as measured by Raman spectroscopy. 

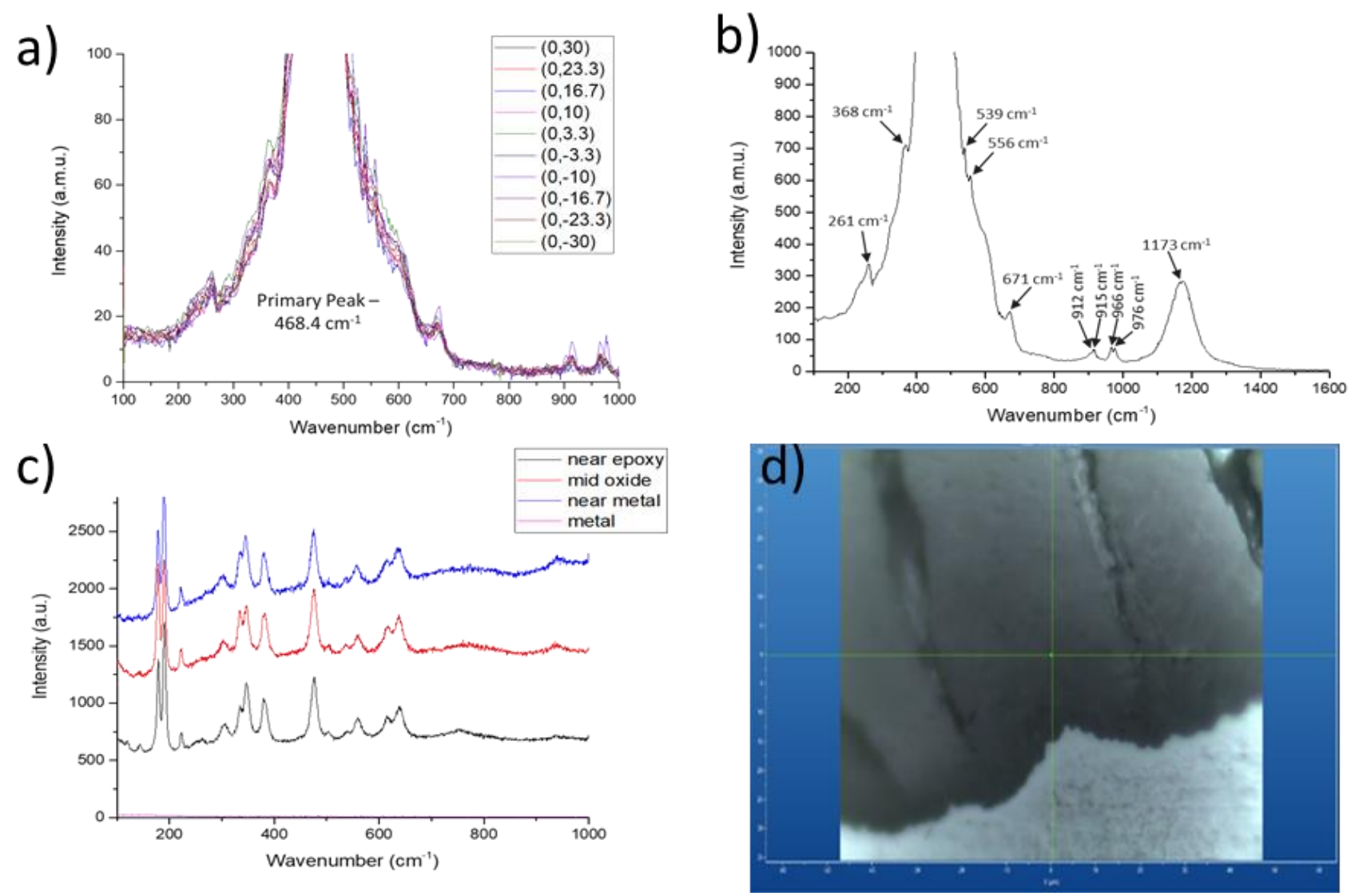

Figure 15. Raman spectra obtained multiple positions (a) on a linear scan of $\mathrm{CeO}_{2}$ pellet (from INL lead), and preliminary identification of peaks referenced from existing published data (b). Raman mapping along the oxide formed on the surface of a $\mathrm{Zr}-2.6 \mathrm{Nb}$ alloy (c) and corresponding optical microscope image (d).

\section{Establishment of Atom Probe Tomography (APT) characterization ability}

APT will be used to reveal the atomic distribution within nuclear fuel, indicating the spatial distribution of element in non-stoichiometric oxide fuel. APT provides nano-scale surface, bulk and interfacial materials analysis of simple and complex structures with atom by atom identification and accurate spatial positioning. APT can provide quantitative information regarding the stoichiometry of clusters within the oxide fuel or cladding hydrides. This effort utilized the Local Electrode Atom Probe (LEAP) at Microscopy and Characterization Suite (MaCS) housed in the center for advanced energy studies (CAES) for APT characterization. With the LEAP, a high frequency voltage or a pulsed laser is applied to the needle-shaped sample to ionize and evaporate atoms from the sample surface, which are then accelerated towards a detector. The detector captures the location of incidence and the time-of-the-flight of the ion traveling from the pulse to the detector. The collected data include the spatial location of 
each incident ion and a spectrum of time-of-the-flight measurement peaks, which allows for elemental identification.

Procedures of fabricating APT needles using dual-beam focused ion beam (FIB) milling were successfully established with both a $\mathrm{CeO}_{2}$ sample and Zircaloy samples. The samples will then cut and mounted onto the silicon posts using platinum deposition and then milled to needle shape with tip radius $\leq 50 \mathrm{~nm}$. Successful FIB needle preparation was accomplished for oxidized $\mathrm{Zr}$ alloy samples and APT analysis was conducted (Figure 2). However difficulty was encountered with $\mathrm{CeO}_{2}$ and needle fabrication was not successful for the ceramic sample for the first trial (Figure 2a). Difficulty with the $\mathrm{CeO}_{2}$ sample was not unexpected as making ceramic needle samples for APT is very challenging and the high porosity within the sample was the major reason for the failure. A second attempt will be conducted with a more dense oxide sample that is currently being synthesized and characterized as part of a partner work package objective. 

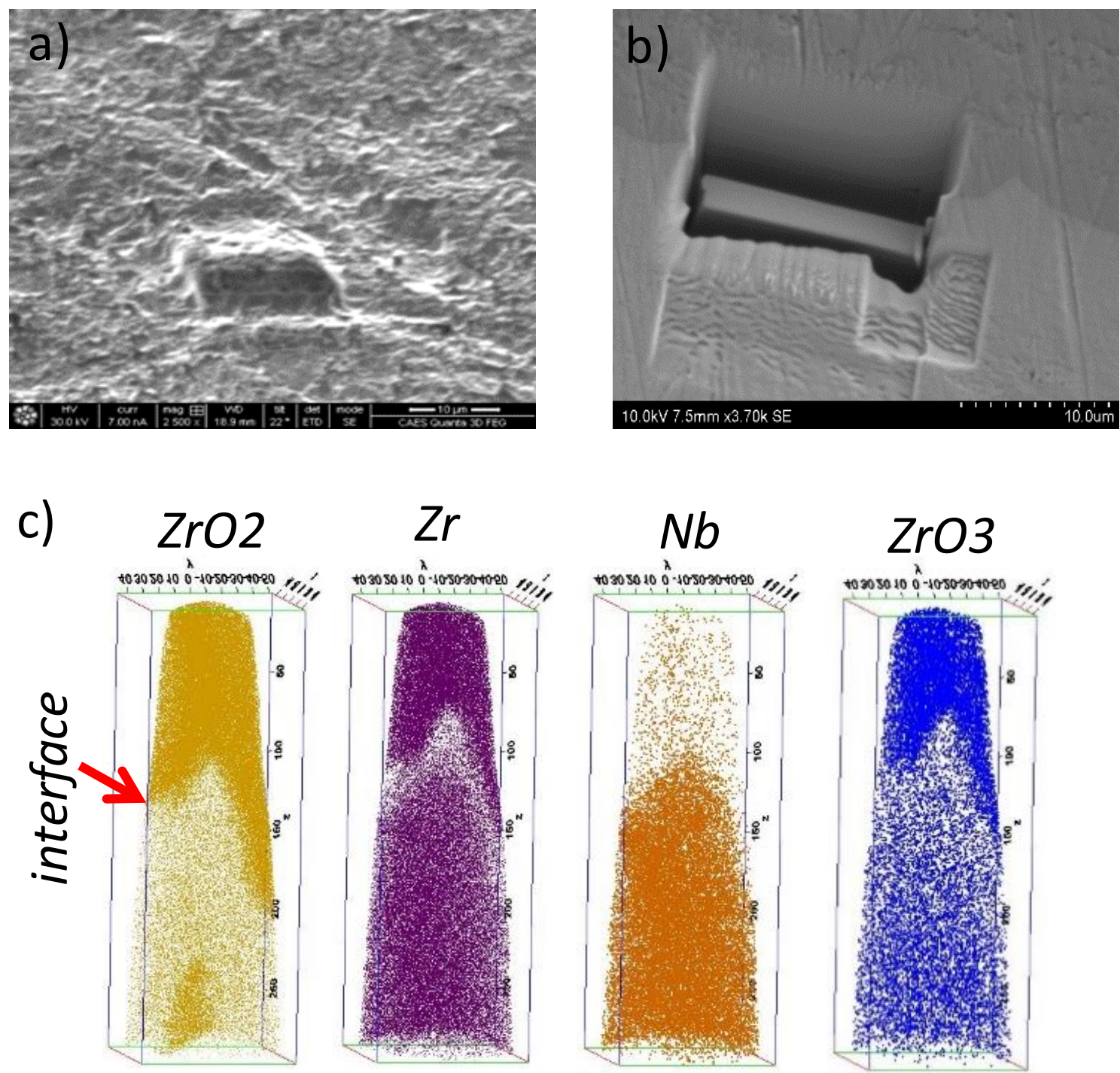

\section{Volume size: $103.8 \times 97.9 \times 285.7 \mathrm{~nm}^{3}$}

Figure 16. SEM image showing the spot where APT needle preparation using FIB milling of $\mathrm{CeO}_{2}$ pellet (from INL lead) was attempted (a), SEM image of the $\mathrm{Zr}-2.6 \mathrm{Nb}$ sample metal/oxidation interface FIB milling region (b) where needles were extracted for APT analysis (c) capturing the metal/oxide interface.

\section{Pursuit of Synchrotron X-ray Microscopy and Spectroscopies}

High-energy synchrotron X-ray tomography and spectroscopies are powerful tools to determine the structure of defects within oxide fuels and to monitor hydride formation on Zircaloy cladding. High-energy synchrotron X-ray diffraction (XRD) has been proved to be efficient in determine different phases of hydride cladding and the reorientation of the hydride in irradiated 
nuclear fuel cladding. X-ray absorption near edge structure (XANES) and extended X-ray absorption fine structure (EXAFS) provide information on the long range and short range chemical disorder in addition to the oxidation state of the probed elements, which is useful to determine the order-disorder in non-stoichiometric oxide fuel. Bulk samples can be used in both technique with different thickness requirement. A proposal for beam time at beamline 1D-D at the Advanced Photon Source to do integrated synchrotron XRD and tomography for characterization in-situ as the chemistry evolves with elevated temperature was submitted. It was not awarded in the spring cycle but the proposal will be resubmitted. Although beamtime was not awarded, progress on this milestone is not impeded as we have established support from the beamline scientist (Dr. Jon Almer) and will be able to better refine the experimental parameters and material samples to be characterized to more closely align with the work package objectives and EIS characterization capability being established by our INL partner.

\section{Recruitment and hiring of a graduate and undergraduate research assistant}

A graduate student was identified, recruited, and hired to support this research effort in conjunction with an undergraduate research assistant. Corey Efaw is currently pursuing his $\mathrm{PhD}$ in materials science at BSU and was funded on this project to work with undergraduate research assistant, as planned. 


\section{References}

1. S.P.S. Badwal and J. Drennan, Yttria-Zorconia: Effect of Microstructure on Conductivity, J. Mater. Sci., 22 3231-9 (1987).

2. R.E.W. Casselton, Low Field DC Conduction in Yttria-Stabilized Zirconia, Phys. Status Solidi A, 2[3] 571-85 (1970).

3. Y. Dong, L. Qi, J. Li, and I.W. Chen, A Computational Study of Yttria-Stabilized Zirconia:

II. Cation Diffusion, Acta Mater., 126 438-50 (2017).

4. H. He et al., Electrochimica Acta, 92 (2013), 148.

5. T. He, K.D. Kreuer, Yu.M. Baikov and J. Maier, Solid State Ionics 95 (1997),301

6. H. K. Jenssen, R. Szoke, N.O. Solum, A. Palencsar. PIE results and mechanistic interpretation on on-line EIS data from the cladding corrosion test IFA-731. HWR-1156. OECD Halden Reactor Project. 2017.

7. T.F. Kelly and M.K. Miller. 2007. Invited Review Article: Atom Probe Tomography. Review of Scientific Instruments 78, 031101 (2007)

8. K.D. Kreuer, Th. Dippel, Yu.M. Baikov and J. Maier, Solid State Ionics 86-88 (1996), 613.

9. A. Leonide, V. Sonn, A. Weber, E. Ivers-Tiffée, J. Electrochem. Soc. 155 (1), B36 (2008).

10. M.E. Orazem and B. Tribollet. 2008. Electrochemical Impedance Spectroscopy. John Wiley \& Sons Inc. Hoboken, New Jersey.

11. J.H. Park and R.N. Blumenthal, Electronic Transport in 8 Mole Percent Y2O3-ZrO2, J.

Electrochem. Soc., 136 2867-76 (1989).

12. M.R. Tonks, R. Williamson, and R. Masson. 2015. Chapter 22: Finite Element Modelling. NEA/NSC/R (2015)5. http://www.iaea.org/inis/collection/NCLCollectionStore/_Public/47/032/47032428.pdf

13. A.K. Tyagi and S. Banerjee. 2017. Materials Under Extreme Conditions: recent trends and future prospects. Technology \& Engineering. Elsevier.

14. M. Yashima, M. Kakihana, and M. Yoshimura, Metastable-Stable Phase Diagrams in the Zirconia-Containing Systems Utilized in Solid-Oxide Fuel Cell Application, Solid State Ionics, 86 1131-49 (1996)

15. D.B. Williams, C.B. Carter (1996) The Transmission Electron Microscope. In: Transmission Electron Microscopy. Springer, Boston, MA

16. Y. Zhang et al., Current Opinion In Solid State and Materials Science, 19 (2015), 19. 